\title{
The role of moderating factors in user technology acceptance
}

\author{
Heshan Sun*, Ping Zhang \\ School of Information Studies, Syracuse University, USA
}

Received 19 February 2004; received in revised form 7 March 2005; accepted 11 April 2005

Available online 2 June 2005

Communicated by S. Wiedenbeck

\begin{abstract}
Along with increasing investments in new technologies, user technology acceptance becomes a frequently studied topic in the information systems discipline. The last two decades have seen user acceptance models being proposed, tested, refined, extended and unified. These models have contributed to our understanding of user technology acceptance factors and their relationships. Yet they have also presented two limitations: the relatively low explanatory power and inconsistent influences of the factors across studies. Several researchers have recently started to examine the potential moderating effects that may overcome these limitations. However, studies in this direction are far from being conclusive. This study attempts to provide a systematic analysis of the explanatory and situational limitations of existing technology acceptance studies. Ten moderating factors are identified and categorized into three groups: organizational factors, technological factors and individual factors. An integrative model is subsequently established, followed by corresponding propositions pertaining to the moderating factors.
\end{abstract}

(C) 2005 Elsevier Ltd. All rights reserved.

Keywords: User technology acceptance; Conceptual research; Moderating factors; Research model

\section{Introduction}

Driven by market competitiveness, business enhancement, service improvement and work efficiency, organizations have invested heavily in information technology with the likelihood of continuing this investment pattern into the foreseeable future (Chau and $\mathrm{Hu}, 2002$ ). Some estimates show that since the 1980 s, $50 \%$ of all new capital investment in organizations has been in information technology (Venkatesh et al., 2003). Understanding the factors that influence user technology acceptance and adoption in different contexts continues to be a focal interest in information systems (IS) research.

Several models and theories have been developed to explain user technology acceptance behavior. However, these models have some limitations. The first limitation concerns the explanatory power of the models. Most of the existing studies account for less than $60 \%$ of variance explained, especially those using field studies with profes-

\footnotetext{
*Corresponding author. Tel.: + 13154789183.

E-mail addresses: hesun@syr.edu (H. Sun),pzhang@syr.edu (P. Zhang).
}

sional users. Although there may be many other factors that are beyond researchers' reach, the differences in explanatory power between laboratory studies and field studies, and between studies using students and using professionals, imply some complex contextual factors in the real world that should be taken into account (e.g., the influence of organizational factors such as the voluntariness of IT usage). The second limitation of these models is the inconsistent relationships among constructs, making researchers question the generalizability of these models across differing contexts (e.g., Lee et al., 2003; Legris et al., 2003). These limitations call for improvement and refinement of existing studies.

Moderating factors may account for both the limited explanatory power and the inconsistencies between studies. In an early study, Adams et al. (1992) called for more examination of moderating factors. Several recent studies continue to call for the inclusion of some moderating factors (e.g., Lucas and Spitler, 1999; Venkatesh et al., 2003). Agarwal and Prasad (1998) explicitly criticized the absence of moderating influences in technology acceptance model (TAM), and called for more research to investigate moderating effects. Venkatesh et al. (2003) tested eight 
models and found that the predictive validity of six of the eight models significantly increased after the inclusion of moderating variables. Furthermore, they argued, "it is clear that the extensions (moderators) to the various models identified in previous research mostly enhance the predictive validity of the various models beyond the original specifications" (Venkatesh et al., 2003, p. 21). In addition, Chin et al. (2003) empirically examined and confirmed the significant influence of moderating factors in existing models of user technology acceptance.

While stating that "the extensive prior empirical work has suggested a large number of moderators", Venkatesh et al. (2003, p. 21) included only four in their study: experience, voluntariness, gender and age. Based on a careful literature review, we believe that there are more moderating factors with empirical evidence than the four studied. For example, the nature of the tasks may affect users' acceptance of technology, as does the nature of the technology. Few of these moderators were examined either conceptually or empirically in recent efforts. A systematic examination of significant moderating factors should contribute to our better understanding of the dynamics of the user technology acceptance phenomenon.

This study examines the moderating effects in user technology acceptance. It adds to the few studies that take into account the individual and contextual factors in technology acceptance (i.e., Igbaria et al., 1997). The objectives of this paper are three-fold. It first provides an overview of prior literature to disclose the limitations of explanatory powers and the inconsistencies between prior studies. Then the paper highlights the moderating factors that account for both the limitations of the explanatory power and the inconsistencies. Ten moderating factors that have strong empirical evidence are identified and categorized into three groups: organizational factors, technological factors and individual factors. And, finally, the paper proposes a new model with propositions pertaining to the effects of the moderating factors. Readers interested in other aspects of user technology acceptance research summaries, such as research emphases and evolutions, empirical sample sizes and characteristics, most influential authors, and critical comments from several major researchers, are encouraged to read a recent meta analysis by Lee et al. (2003), which lacks discussion of the effects of the moderating factors.

This study calls for more research attention to individual and contextual factors that are often neglected in technology acceptance studies but can be critical in applying theoretical models to specific situations in organizations. The study also provides a basis for further empirical investigation in this research area.

\section{Overview of prior literature}

A variety of models from different perspectives and at various levels have been developed to explain IT acceptance perceptions and behaviors: TAM (Davis, 1989; Davis et al., 1989), Computer Self-Efficacy (Compeau and Higgins, 1995a, b), Task-Technology Fit (Goodhue, 1995; Goodhue and Thompson, 1995), Motivational Model (Davis et al., 1992) and adapted Theory of Planned Behavior (Mathieson, 1991; Taylor and Todd, 1995b). These models have all been recognized in the ISs discipline. Using TAM as an example, abundant studies have been done to test (Davis, 1989, 1993; Davis et al., 1989; Adams et al., 1992), extend(Venkatesh and Davis, 1996, 2000; Igbaria et al., 1997; Venkatesh, 2000; Viswanath and Davis, 2000), or compare it with other models (Davis et al., 1989; Mathieson, 1991; Taylor and Todd, 1995b; Dishaw and Strong, 1999; Venkatesh and Davis, 2000). Overall, these theoretical models have contributed to our understanding of user acceptance perceptions and behaviors. In a recent study, a unified theory of acceptance and usage of technology was proposed and tested by integrating some of the prior models (Venkatesh et al., 2003).

However, there is still room for improvement. In this research, we focus on two aspects: the explanatory power of prior user technology acceptance research and the inconsistent relationships between studies.

In order to provide a comprehensive picture of the existing studies, we systematically selected published articles on technology acceptance to conduct the analysis. The articles were selected through the following procedure. First, primary IS journals and databases (such as ABI/ INFORM, WilsonSelect, JSTOR and ACM Digital Library) were systemically searched using a number of seed articles on user technology acceptance. Second, Social Science Citation Index (SSCI, January 1986-September 2003) was searched for the articles citing the above seed articles. Finally, 55 articles (see Appendix A) were chosen based on the following criteria: (1) The article was published in primary IS journals; (2) The article conducted one or more empirical studies of research; (3) User technology acceptance as well as its components received substantive consideration in the article; and (4) The results were presented in detail, followed by corresponding discussions.

\subsection{The limitations of explanatory power}

Our examination indicates that the vulnerability of explanatory power lies in two areas: the relatively low explained power and the variation of explanatory power owing to different research methods (i.e., laboratory experiments and field studies).

\subsubsection{Limited explanatory power of $R^{2}$}

Table 1 shows a comparison between TAM and other models. It indicates that as one of the most successful models, TAM's explanatory power is limited.

In one recent study, Venkatesh et al. (2003) compared eight user acceptance models on explanatory power. Their longitudinal studies showed that these models exhibited explanatory powers in the neighborhood of $40 \%$. That is, 
Table 1

Comparisons of explanatory powers of TAM and other models

\begin{tabular}{|c|c|c|c|c|}
\hline Compared models & Representative studies & Explained variance in TAM & $\begin{array}{l}\text { Explained variance in } \\
\text { compared models }\end{array}$ & Is TAM better? \\
\hline TRA & Davis et al. (1989) & $\begin{array}{l}\text { After } 1 \text {-h introduction: } 47 \% \\
14 \text { weeks later: } 51 \%\end{array}$ & $\begin{array}{l}\text { After } 1 \text {-h introduction: } 32 \% \\
14 \text { weeks later: } 26 \%\end{array}$ & Yes \\
\hline TPB & $\begin{array}{l}\text { Mathieson (1991) } \\
\text { Taylor and Todd (1995a) } \\
\text { Chau and Hu (2002) } \\
\text { Chau and Hu (2001) }\end{array}$ & $\begin{array}{l}69.3 \% \\
52 \% \\
42 \% \\
40 \%\end{array}$ & $\begin{array}{l}60.1 \% \\
57 \% \\
37 \% \\
32 \%\end{array}$ & $\begin{array}{l}\text { Yes } \\
\text { No } \\
\text { Yes } \\
\text { Yes }\end{array}$ \\
\hline TAM2 & Venkatesh and Davis (2000) & $40 \%$ & $60 \%$ & No \\
\hline $\begin{array}{l}\text { TTF/integrated TAM with } \\
\text { TTF }\end{array}$ & Dishaw and Strong (1999) & $36 \%$ & $41 \% / 51 \%$ & No \\
\hline Extended TAM & Moon and Kim (2001) & $\begin{array}{l}\text { Attitude: } 0.332 \\
\text { BI: } 0.349\end{array}$ & $\begin{array}{l}\text { Attitude: } 0.371 \\
\text { BI: } 0.382\end{array}$ & No \\
\hline
\end{tabular}

Table 2

Comparisons of explanatory powers among eight models (source: Venkatesh et al., 2003)

\begin{tabular}{|c|c|c|c|c|c|c|c|c|}
\hline \multirow[t]{2}{*}{ Models } & \multicolumn{4}{|c|}{ Voluntary context ${ }^{\mathrm{a}}$} & \multicolumn{4}{|c|}{ Mandatory context } \\
\hline & Time $1^{\mathrm{b}}$ & Time 2 & Time 3 & Avg. & Time 1 & Time 2 & Time 3 & Avg. \\
\hline TAM/TAM2 & 0.38 & 0.36 & 0.37 & 0.370 & 0.39 & 0.41 & 0.36 & 0.387 \\
\hline Theory of reasoned action (TRA) & 0.3 & 0.26 & 0.19 & 0.250 & 0.26 & 0.26 & 0.17 & 0.230 \\
\hline Motivational model (MM) & 0.37 & 0.36 & 0.37 & 0.367 & 0.38 & 0.4 & 0.35 & 0.377 \\
\hline Theory of planned behavior (TPB)/decomposed TPB & 0.37 & 0.25 & 0.21 & 0.277 & 0.34 & 0.28 & 0.18 & 0.267 \\
\hline Combined TAM-TPB (C-TAM-TPB) & 0.39 & 0.36 & 0.39 & 0.380 & 0.36 & 0.35 & 0.35 & 0.353 \\
\hline Model of PC utilization (MPCU) & 0.37 & 0.36 & 0.38 & 0.370 & 0.37 & 0.4 & 0.37 & 0.380 \\
\hline Innovation diffusion theory (IDT) & 0.38 & 0.37 & 0.39 & 0.380 & 0.38 & 0.42 & 0.37 & 0.390 \\
\hline Social cognitive theory (SCT) & 0.37 & 0.36 & 0.36 & 0.363 & 0.38 & 0.39 & 0.36 & 0.377 \\
\hline
\end{tabular}

${ }^{\mathrm{a}}$ Voluntary and mandatory contexts are considered to have different impacts on user technology acceptance.

${ }^{\mathrm{b}}$ The time of measurement is considered as an indicator of experience.

these models can explain around $40 \%$ of variances in user behavioral intentions (BIs) (Venkatesh et al., 2003). Table 2 shows the explanatory powers of each model at different data collection times, with the average explanatory powers of each model presenting at less than $40 \%$.

\subsubsection{The difference in explanatory power between experiments and field studies}

Among the studies on user technology acceptance, the dominant methods are laboratory experiment and field study. Experiments are typically conducted with students in a university laboratory environment. The predominant concern with the laboratory experiment method involves convenience sampling (students) and the controlled or artificial context/environment (i.e., Legris et al., 2003). Field studies usually survey subjects in real working environments and contexts by utilizing questionnaires at one time or at different points of time. Sometimes, rather than using self-reporting survey, usage is also observed and recorded directly. Table 3 summarizes the explanatory power of existing studies that are grouped into three clusters: experiments, field studies using professional users and field studies using students. Fig. 1 depicts the results in Table 3.

Table 3 and Fig. 1 demonstrate that studies using experiments have relatively higher explanatory powers than field studies, i.e., the prior models work better for laboratory experiments than for field studies. One suggested reason is "the relatively uncontrolled environment of the field setting" (Lucas and Spitler, 1999). Therefore, the difference in explanatory power between field studies and experiments calls for the inclusion of additional factors that reflect real world settings and conditions. $\mathrm{Hu}$ et al. (1999) explicitly called for "a contingency approach that incorporates additional factors relevant to physicians' decisions to accept telemedicine technology".

Also notable is the general trend that even in field studies, there seem to be some differences in explanatory power. As Fig. 1 indicates, besides a few exceptions with extremely low explanatory powers (some of them were discussed by the authors in the original studies, as noted in Table 3), the field studies using students as subjects have 


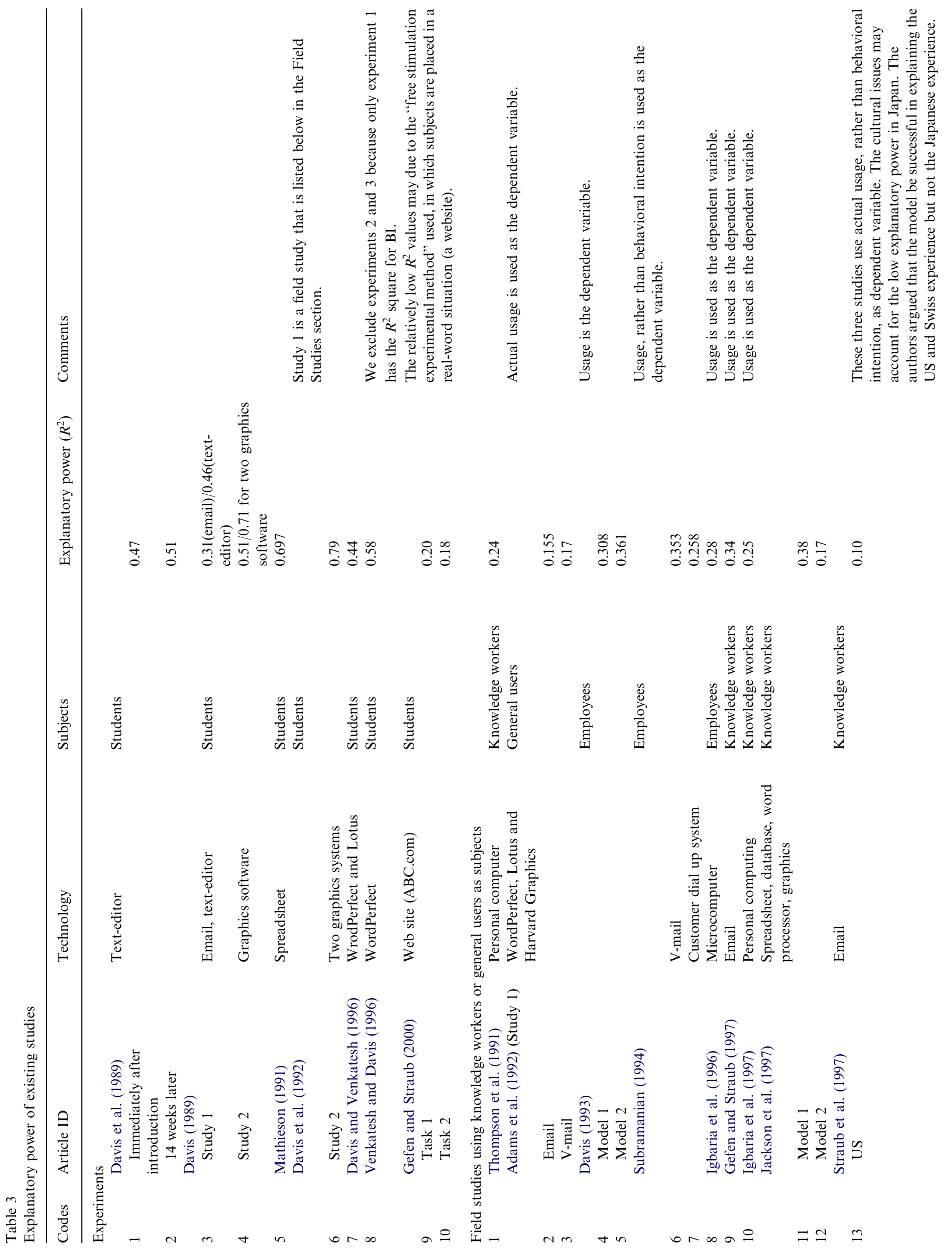




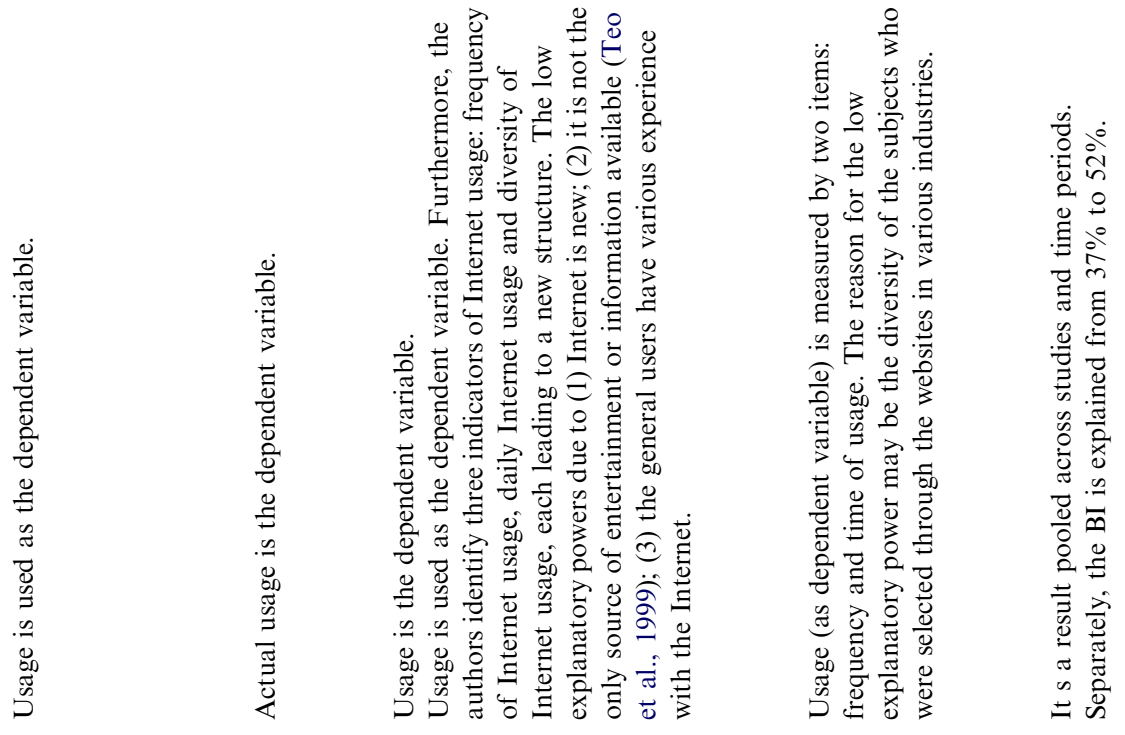

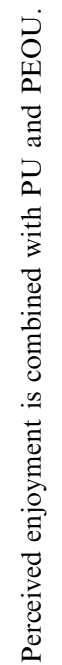

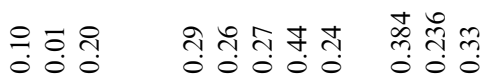

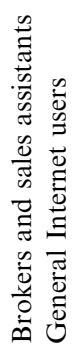

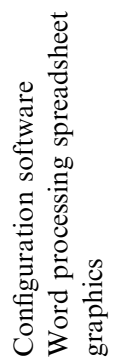

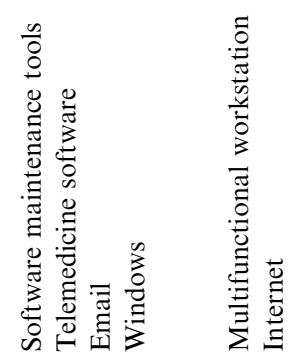

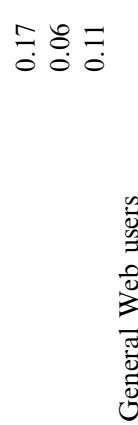

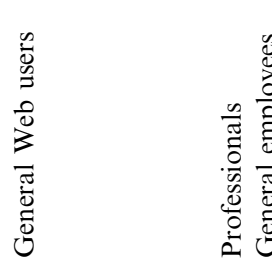

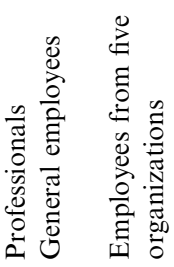

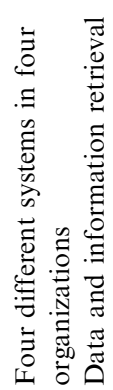

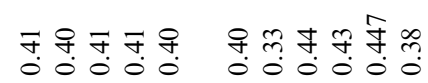

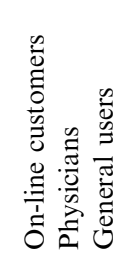

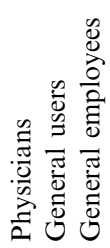

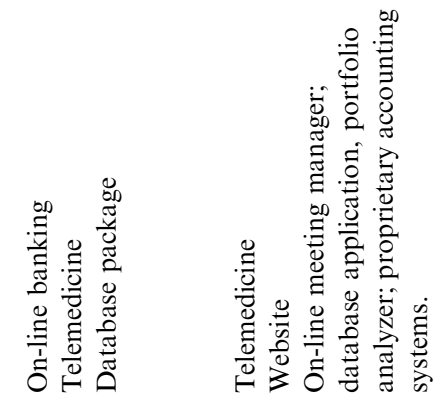

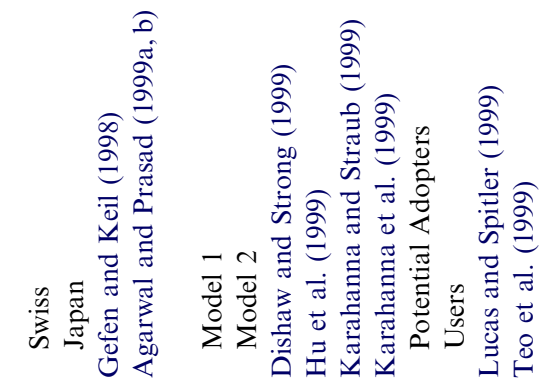

ปேำ

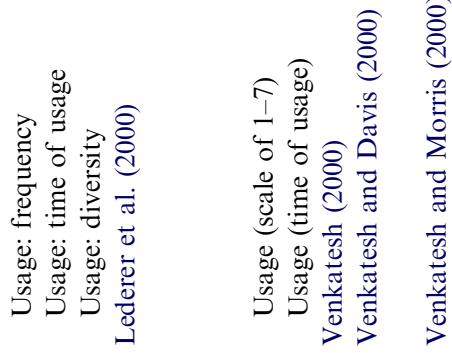

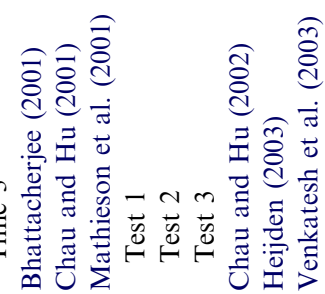

นิํํำ

수슜

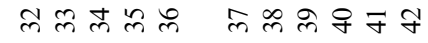




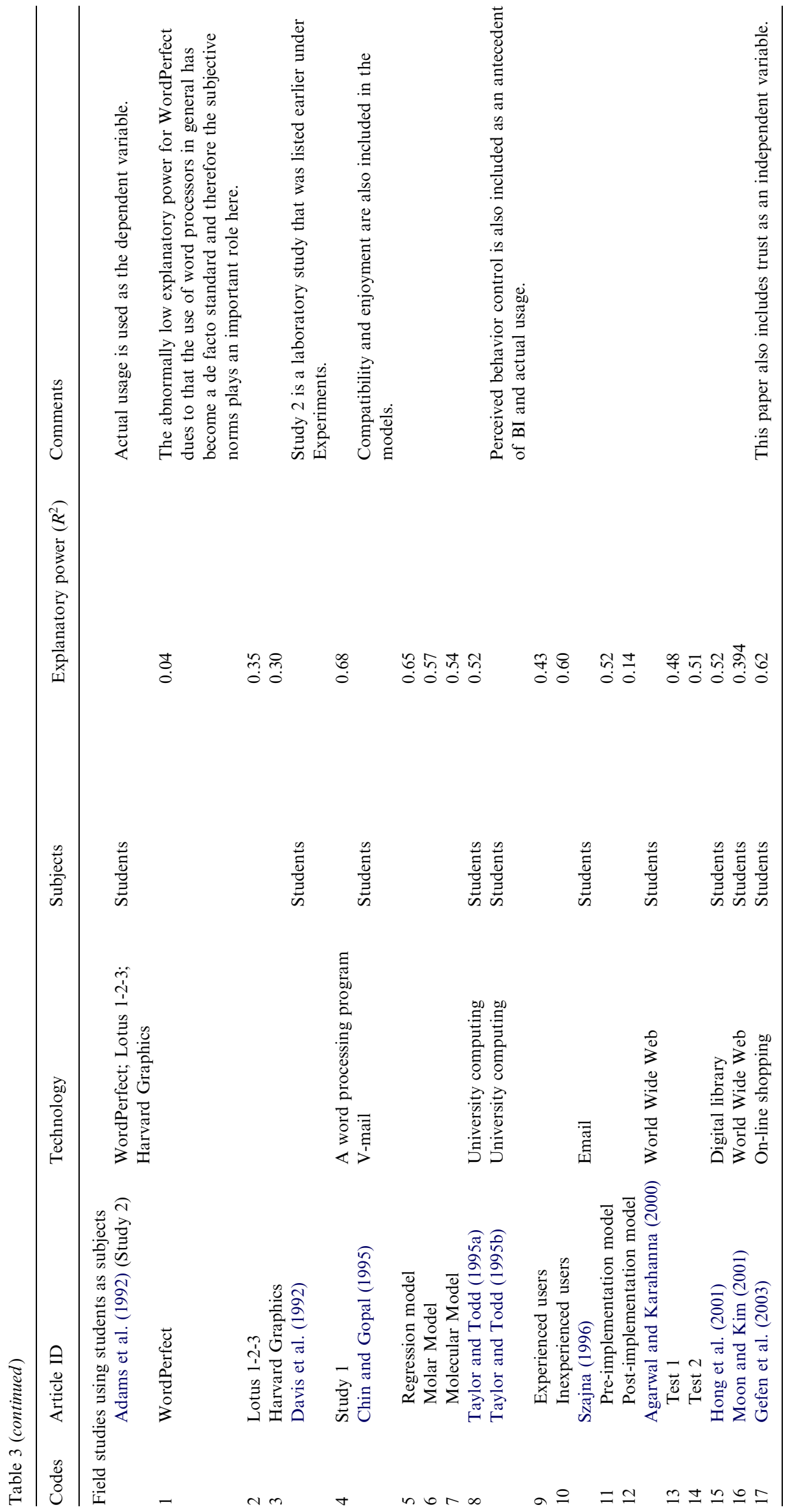



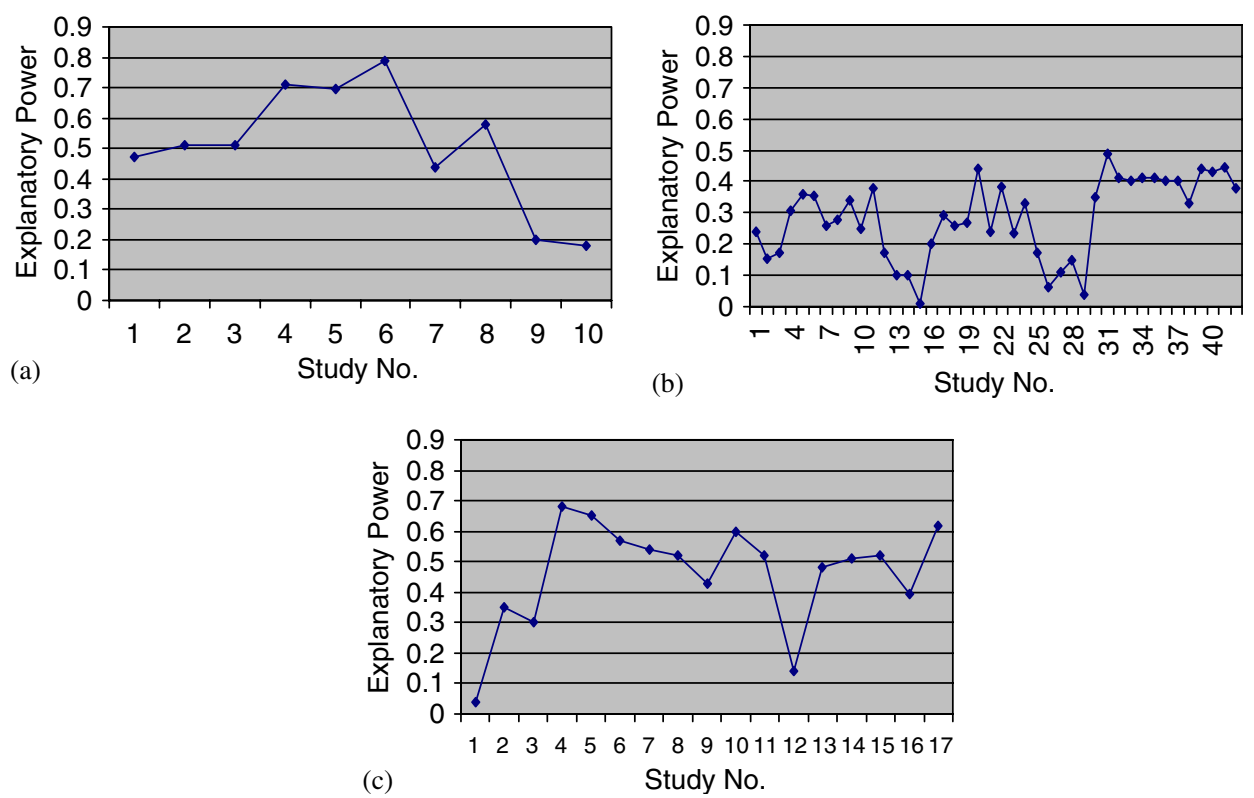

Fig. 1. Explanatory powers of existing studies: (a) experiments (10 studies); (b) field studies using professionals (42 studies); (c) field studies using students (17 studies).

higher explanatory powers than the field studies using general users (such as knowledge workers and other professionals). Under the assumption that employees face more complex and differing factors in real contexts than students do, the difference also calls for additional factors that may explain more variance in user acceptance.

\subsection{Inconsistencies of major relationships}

While quite a number of factors pertaining to user acceptance have been identified, we will focus on the major constructs based on prior findings, including subjective norm (SN), perceived usefulness (PU), perceived ease of use (PEOU), attitude (AT), behavioral intension (BI) and actual usage. Among these constructs, $\mathrm{SN}$ is the least studied construct in existing models. We decided to include it in our study because it is considered an important factor in several models (e.g., theory of reasoned action (TRA), TPB, Model of PC Utilization), has been included in the TAM2 model, receives empirical supports, and is viewed as a "core construct" (Venkatesh et al., 2003).

The abundant empirical evidence suggests the main relationships, as shown in Table 4 and Fig. 2. Among the 54 articles examined in this paper, 48 of them contributed a total of 72 empirical tests/studies. The other six, although useful for our arguments in other sections of this study, did not test these main relationships. Table 4 summarizes the review of these main relationships, which shows two major patterns. First, the constructs studied are varied. For example, some studies use AT while others use BI or actual usage as the indicator of user acceptance. Second, some main relationships are inconsistent. For example, PEOU has significant effects on BI in some studies but not in others.
By summarizing the data in Table 4 into the picture in Fig. 2, some interesting findings start to emerge. First, most of the relationships are statistically significant in prior studies, indicating certain robustness of TAM. Second, its relationships are not completely consistent in prior studies. All relationships except for the one between $\mathrm{SN}$ and PU have controversial results. Third, the robustness levels of the relationships are different. For example, the impacts of PU on AT, on BI and on usage seem more robust than those of PEOU. Next, we will discuss these relationships in detail.

\subsubsection{Perceived usefulness}

Usefulness is defined as "the degree to which a person believes that using a particular technology will enhance his performance" (Davis, 1989, p. 320). There are several similar counterpart constructs in other models, such as the outcome expectation in the Computer Self-Efficacy model and the extrinsic motivation in the Motivational Model. These similar concepts confirm from different angles that PU plays an important role in forming a user's AT or BI.

PU has been confirmed as an important, if not the most important, factor that influences user technology acceptance and therefore has received a great deal of attention from prior researchers. Almost all (71 out of 72) of the prior studies test the effects of PU (Table 4). Fig. 2 indicates that PU has significant influence on AT, BI or Usage, with few exceptions.

In TAM2, PU's antecedents, including SN, image, job relevance, output quality and result demonstrability, are identified (Venkatesh and Davis, 2000). In all, 40-60\% of its variance (in four longitudinal studies) is explained. $\mathrm{SN}$ is empirically confirmed to be the most influential determinant of PU, especially when users have little 


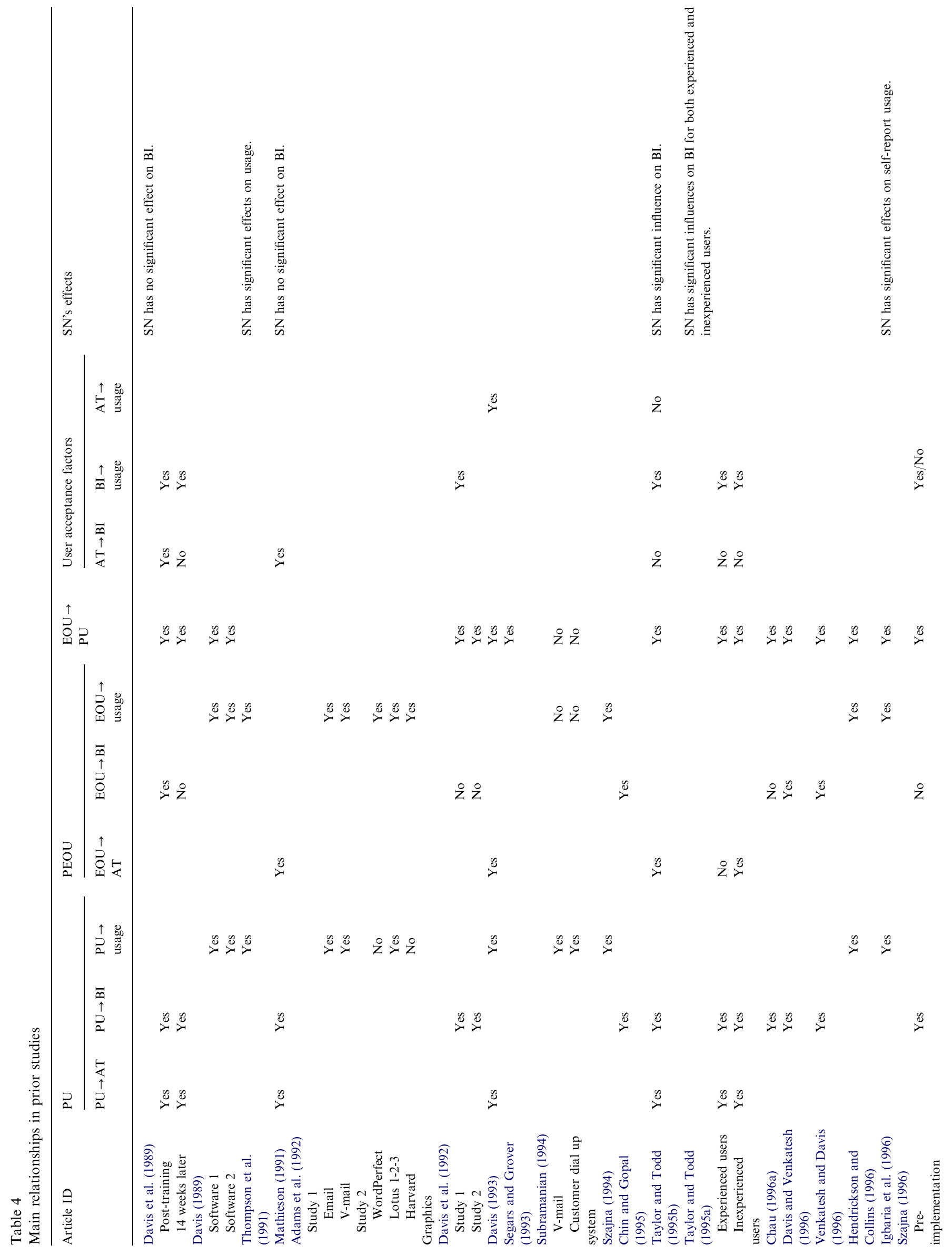



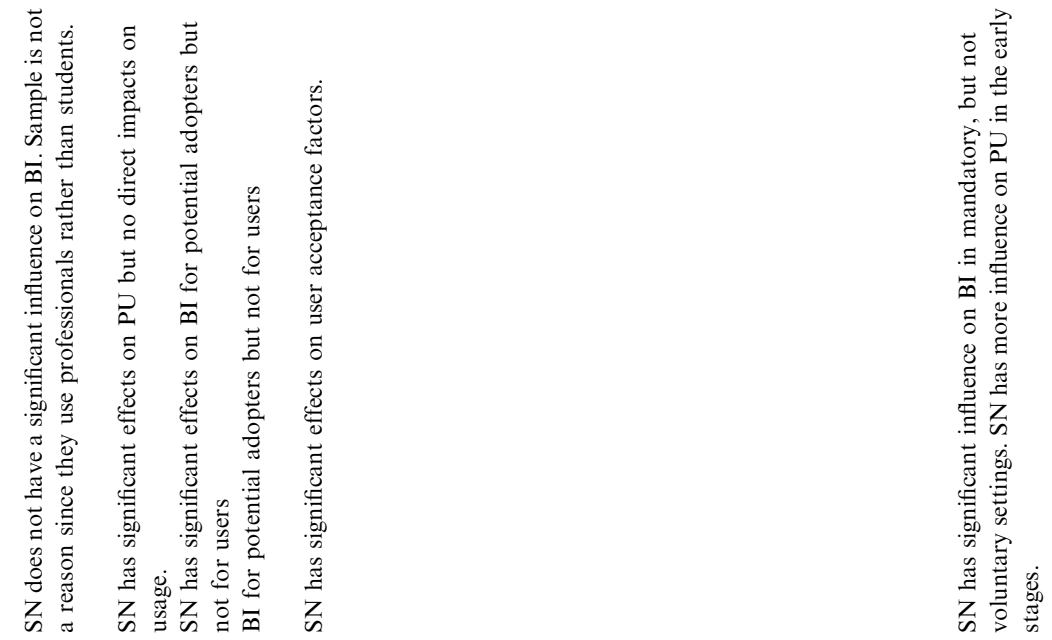

$$
\text { z } \quad \dot{\sim}
$$

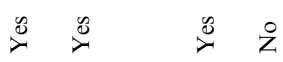

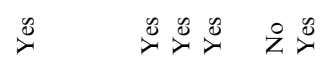

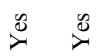
$\sum \stackrel{\infty}{-\infty}$
$\stackrel{\infty}{\infty}$

$$
\stackrel{\infty}{\nearrow}
$$
z
zo
z $\stackrel{0}{0}$
$\stackrel{3}{2}$

そ)

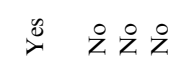

ż

$\sum^{\infty} \sum^{\infty}$

$\sum_{i}^{\infty}$

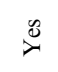

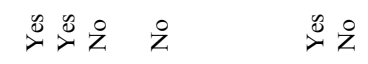

$\stackrel{\infty}{\infty} \overbrace{\infty}^{\infty}$

$\stackrel{0}{2} \stackrel{0}{\infty}$

z

$\sum_{\infty}^{\infty}$

$\stackrel{\infty}{0}$

之

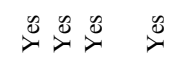

z

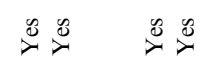

$\sum_{i}^{\infty}$

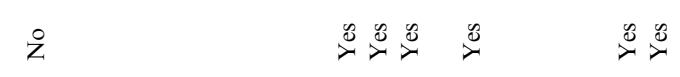

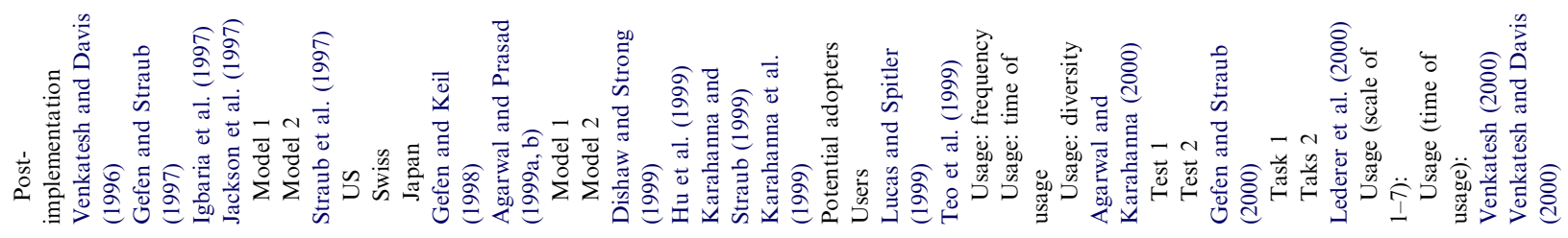




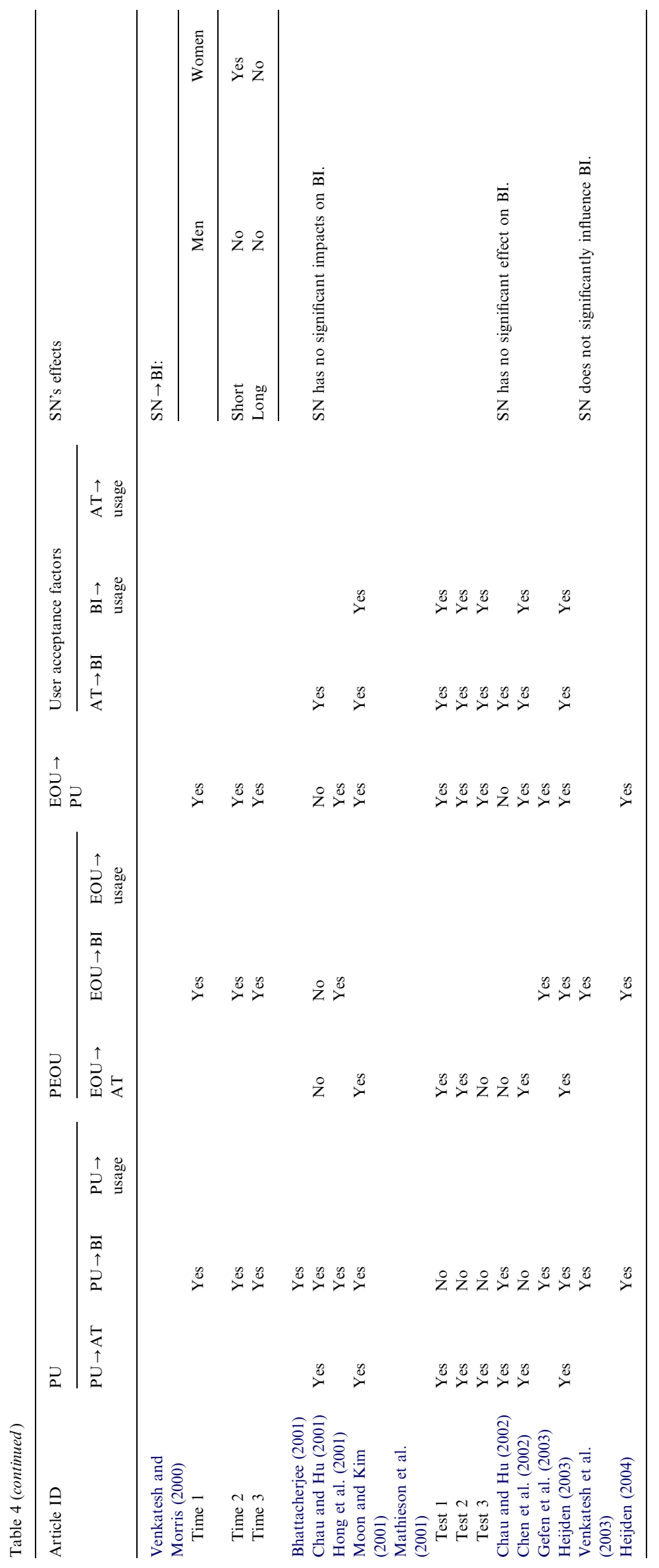




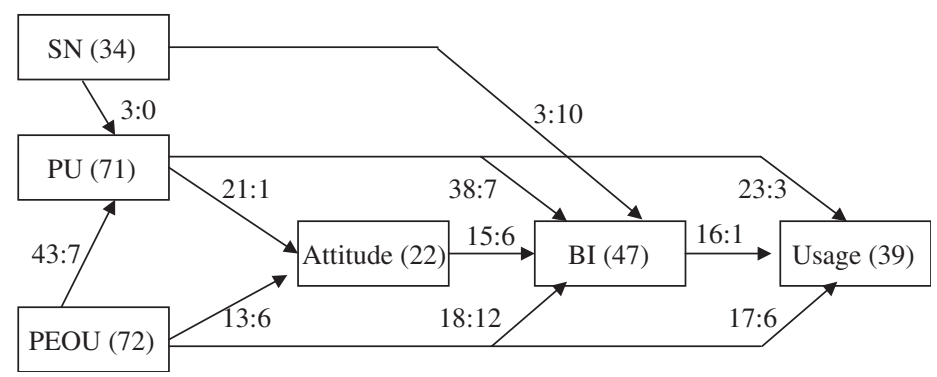

Fig. 2. Summary of relationships (number of studies $w$ /significant linkages: number of studies $w /$ insignificant linkages). Note: (1) The number following each factor is the total number of studies (not articles) in which this factor is studied. (2) BI: behavioral intention; SN: subjective norm; PU: perceived usefulness; PEOU: perceived ease of use.

experience with the technology (Venkatesh and Davis, 2000).

\subsubsection{Perceived ease of use}

PEOU refers to "the degree to which a person believes that using a particular system would be free of effort" (Davis, 1989, p. 320). Unlike PU, the effects of PEOU on AT, BI and usage are quite inconsistent. Fig. 2 indicates that among the studies we reviewed, 18 studies show significant and 12 non-significant impact of PEOU on BI. This result is consistent with what Lee et al. (2003) claimed, that compared with PU, PEOU is an unstable measure in predicting BI.

These inconsistencies suggest that some factors may moderate the linkages between PEOU and the other three constructs: AT, BI and Usage. Igbaria et al. (1997) argued that experience might be one of the moderating factors. Subramanian (1994) stated two reasons for the inconsistent PEOU effects. The first addressed the complexity of the systems being studied: some (such as voice mail (v-mail) and customer dial-up systems) were relatively easier to use than some other software packages or systems, such as Harvard Graphics or spreadsheets (Subramanian, 1994), and it happened that in the latter case, PEOU was found significant (Adams et al., 1992). The second reason was the users' experience. Additionally, Venkatesh and Morris (2000) found that gender also has a moderating effect on the PEOU-related linkages.

PEOU has shown a significant effect on PU in the majority of studies (Davis, 1989; Davis et al., 1989; Mathieson, 1991; Taylor and Todd, 1995a,b; Szajna, 1996; Venkatesh and Davis, 2000). As Fig. 2 shows, in 43 out of 50 studies, PEOU $\rightarrow$ PU links appear significant. Exceptions were found in Chau and Hu's (2002) research, where PEOU has no effect on PU. The authors attributed this to the fact that professional users (physicians in their study) were different from general users in terms of intellectual capacity (Chau and $\mathrm{Hu}, 2002$ ). Professional users like physicians have relatively high intellectual capacity and therefore are less likely to depend on ease of use to form their intentions. Studies have also shown that experience may be another factor moderating the relation- ship between PEOU and PU. The more experienced the users are, the less the effect of PEOU on PU (Szajna, 1996).

\subsubsection{Dependent variables: attitude, behavior intention and usage}

The strong $\mathrm{BI} \rightarrow$ Usage link has received empirical support from a large number of studies (Davis et al., 1989; Taylor and Todd, 1995a, b; Szajna, 1996; Venkatesh and Davis, 2000). As indicated in Fig. 2, 16 out of 17 studies considering the $\mathrm{BI} \rightarrow$ Usage link show significant results. BI has been found to be a better predictor of systems usage than competing predictors such as realism of expectations, motivational force, value and user satisfaction (Venkatesh and Davis, 1996).

Compared with BI, the results about AT are not so consistent. As Table 4 and Fig. 2 show, AT's significant effects on BI were shown in 15 studies, but in the other six. AT was omitted from the final TAM because the PU $\rightarrow$ BI link seemed more significant (Davis et al., 1989). This can be explained in that if a system is perceived to be useful, people may have a high BI even though they do not have a positive AT toward it (Davis et al., 1989). Another explanation is that AT is a complex construct with multiple components. Triandis (1980) argued for the separation of the affective (which has a like/dislike connotation) and cognitive components of AT. To do this, Triandis (1980, p. 211) introduced "affect", which was defined as "the feelings of joy, elation, or pleasure, or depression, disgust, displeasure, or hate associated by an individual with a particular act". Many existing models focus mainly on cognitive factors, which only constitute part of AT.

\subsubsection{Subjective norm's effects}

SN refers to "a person's perception that most people who are important to him think he should or should not perform the behavior in question" (Fishbein and Ajzen, 1975). SN has three major mechanisms through which it exerts its influence: compliance, internalization and identification. Compliance is reflected in the direct $\mathrm{SN}-\mathrm{BI}$ relationship, while internalization and identification alter a user's belief structure, such as PU. Therefore, SN has been found to play two separate and different roles: one as the antecedent of $\mathrm{BI}$ and the other as the antecedent of PU. 
Table 5

Inconsistencies in research results of $\mathrm{SN}$

\begin{tabular}{|c|c|c|c|}
\hline Relationships & $\begin{array}{l}\text { Representative works } \\
\text { Significant }\end{array}$ & Non-significant & Possible reasons \\
\hline \multirow[t]{2}{*}{$\mathrm{SN} \rightarrow \mathrm{PU}$} & $\begin{array}{l}\text { Gefen and Straub (1997), Karahanna and } \\
\text { Straub (1999) and Venkatesh and Davis (2000) }\end{array}$ & Venkatesh and Davis (2000) & $\begin{array}{l}\text { Experience (Venkatesh and } \\
\text { Davis, 2000) }\end{array}$ \\
\hline & Venkatesh and Morris (2000) & Venkatesh and Morris (2000) & $\begin{array}{l}\text { Gender (Venkatesh and Morris, } \\
\text { 2000) }\end{array}$ \\
\hline \multirow[t]{5}{*}{$\mathrm{SN} \rightarrow \mathrm{BI}$} & Taylor and Todd (1995a) & Davis et al. (1989) & $\begin{array}{l}\text { Experience (Venkatesh and } \\
\text { Davis, 2000; Venkatesh et al., } \\
\text { 2003) }\end{array}$ \\
\hline & Lucas and Spitler (1999) & Mathieson (1991) & $\begin{array}{l}\text { Gender (Venkatesh and Morris, } \\
\text { 2000; Venkatesh et al., 2003) }\end{array}$ \\
\hline & Venkatesh and Davis (2000) & Dishaw and Strong (1999) & $\begin{array}{l}\text { User professions (Mathieson, } \\
\text { 1991; Chau and } \mathrm{Hu}, 2002 \text { ) } \\
\text { Type of technology (Davis et } \\
\text { al., 1989) }\end{array}$ \\
\hline & Venkatesh and Morris (2000) & Chau and $\mathrm{Hu}(2001)$ & $\begin{array}{l}\text { Voluntariness (Venkatesh and } \\
\text { Davis, 2000; Venkatesh et al., } \\
\text { 2003) }\end{array}$ \\
\hline & Venkatesh et al. (2003) & $\begin{array}{l}\text { Chau and } \mathrm{Hu}(2002) \\
\text { Venkatesh and Morris (2000) } \\
\text { Venkatesh et al. (2003) }\end{array}$ & Age (Venkatesh et al., 2003) \\
\hline
\end{tabular}

Note: Some articles appear in both "significant" and "non-significant" categories because SN shows different effects in different conditions in them (i.e., more than one studies).

Fig. 2 depicts that only three out of 13 studies have a significant $\mathrm{SN} \rightarrow \mathrm{BI}$ relationship. Table 5 summarizes the prior research, in which the impacts of $\mathrm{SN}$ on $\mathrm{BI}$ and $\mathrm{PU}$ are inconsistent. The reasons accounting for such inconsistencies are also indicated. As presented in Table 5, the influence of SN is very complex and "subject to a wide range of contingent influences" (Venkatesh et al., 2003).

In summary, this survey of the literature discloses the limitations of explanatory powers and inconsistencies of the main constructs in prior user technology acceptance studies. These limitations and inconsistencies call for additional consideration regarding individual and contextual differences as described above. In the next section, we further explore the moderating effects in the context of a proposed integrated model and propositions.

\section{An integrated model and propositions}

Prior studies imply great potential regarding the addition of moderating factors to enhance explanatory power. As previously mentioned, studies using student subjects have more explanatory power than those using professionals, which usually have more complex contexts. This is reasonable in that the more complex the context, the more influencing factors are involved in variances, and therefore a given model with only limited factors studied has less explanatory power. In other words, when we face a more complex context, we need additional factors to capture the complexity of the context. Chin et al. (2003) empirically confirmed that the inclusions of moderating factors could enhance the model's explanatory power, although the effect is limited. A prime example is research conducted by Venkatesh et al. (2003) where they compared explanatory power between models with and without moderators, as summarized in Table 6. In general, the explanatory power of the models increases with the inclusion of moderators. For example, when including gender as a moderating variable, the explanatory power (predictive validity) of TAM increases to $52 \%$ compared to approximately $35 \%$ without moderators. Similarly, when including experience and voluntariness as moderating variables, the explanatory power of TAM2 also increases to $53 \%$ from about $35 \%$ without moderators (Venkatesh et al., 2003). Thus, the inclusion of moderators leads to enhancing a model's explanatory power, making investigating moderating effects worthwhile.

The consideration of moderating factors may also contribute to overcoming the inconsistencies in previous studies. As mentioned above, in order to understand why the main relationships shown in Table 4, Fig. 2 and Table 5 are inconsistent, several reasons have been investigated. These reasons, however, are underdeveloped and therefore need more conceptualization and formalization.

Based on the discussion so far, we propose an integrated model as depicted in Fig. 3. Besides the commonly studied constructs, such as PU, PEOU, SN, BI and Usage, moderating factors are highlighted in this model. Ten moderating factors are identified from prior studies and are categorized into three groups: organizational factors, technology factors and individual factors. The development of the propositions about the moderating factors follows. 
Table 6

Comparisons of explanatory power between models with and without moderators (adapted from Venkatesh et al., 2003)

\begin{tabular}{|c|c|c|c|c|c|c|c|}
\hline & \multicolumn{6}{|c|}{ Explanatory power w/out moderators } & \multirow[t]{3}{*}{ Explanatory power $\mathrm{w} /$ moderators } \\
\hline & \multicolumn{3}{|c|}{ Voluntary settings } & \multicolumn{3}{|c|}{ Mandatory settings } & \\
\hline & Time 1 & Time 2 & Time 3 & Time 1 & Time 2 & Time 3 & \\
\hline TAM/TAM2 & 0.38 & 0.36 & 0.37 & 0.39 & 0.41 & 0.36 & $\begin{array}{l}0.52 \text { (TAM) } \\
0.53 \text { (TAM2) }\end{array}$ \\
\hline Theory of reasoned action (TRA) & 0.30 & 0.26 & 0.19 & 0.26 & 0.26 & 0.17 & 0.36 \\
\hline Motivational model (MM) & 0.37 & 0.36 & 0.37 & 0.38 & 0.40 & 0.35 & 0.38 \\
\hline Theory of planned behavior (TPB)/decomposed TPB & 0.37 & 0.25 & 0.21 & 0.34 & 0.28 & 0.18 & $\begin{array}{l}0.36 \text { (TPB) } \\
0.47 \text { (DTPB) }\end{array}$ \\
\hline Combined TAM-TPB (C-TAM-TPB) & 0.39 & 0.36 & 0.39 & 0.36 & 0.35 & 0.35 & 0.39 \\
\hline Model of PC utilization (MPCU) & 0.37 & 0.36 & 0.38 & 0.37 & 0.40 & 0.37 & 0.47 \\
\hline Innovation diffusion theory (IDT) & 0.38 & 0.37 & 0.39 & 0.38 & 0.42 & 0.37 & 0.40 \\
\hline Social cognitive theory (SCT) & 0.37 & 0.36 & 0.36 & 0.38 & 0.39 & 0.36 & 0.36 \\
\hline
\end{tabular}

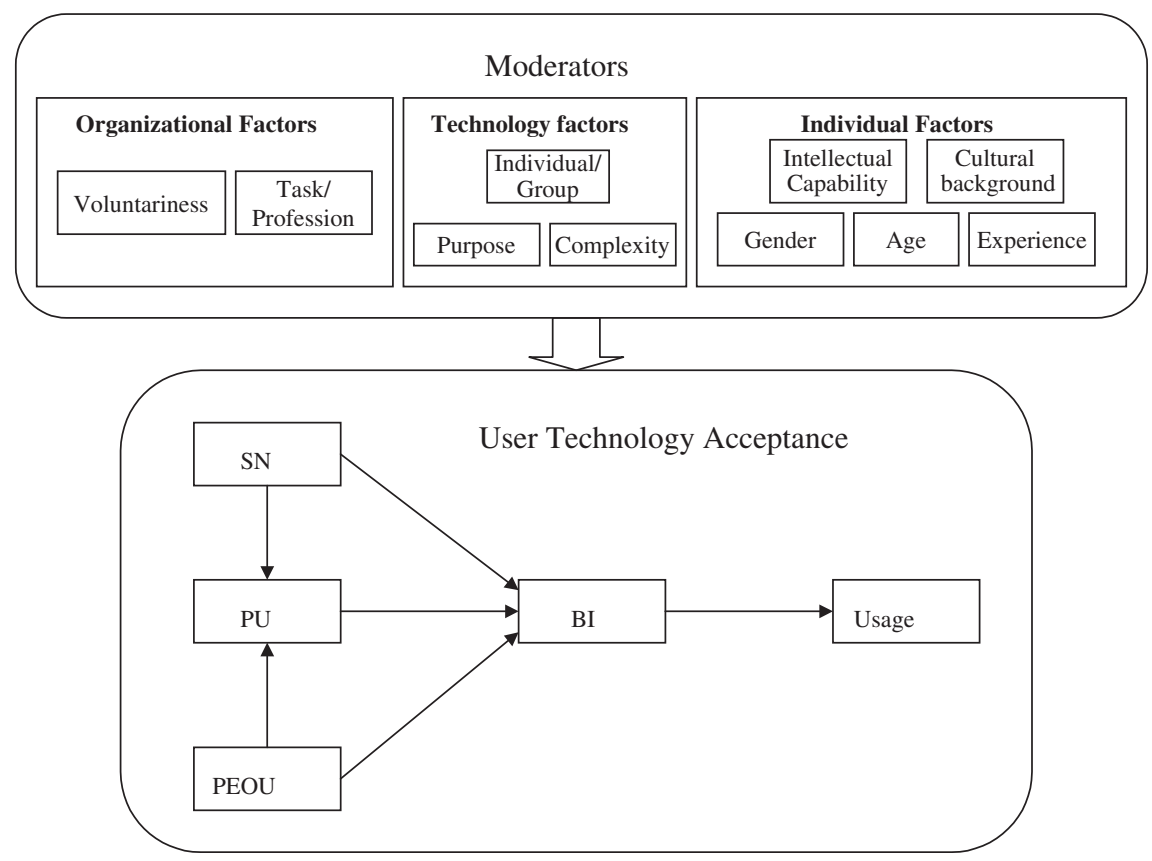

Fig. 3. An integrated model (including moderators). BI: behavioral intention; SN: subjective norm; PU: perceived usefulness; PEOU: perceived ease of use.

\subsection{Propositions for organizational moderators}

Two factors are identified as organizational moderators: voluntariness and the nature of tasks and profession. They both have gained much attention in the literature reviewed.

\subsubsection{Voluntariness}

Voluntariness is defined as the extent to which potential adopters perceive the adoption decision to be nonmandatory (Moore and Izak, 1991; Venkatesh and Davis, 2000). Based on prior studies, voluntariness moderates merely the $\mathrm{SN} \rightarrow \mathrm{BI}$ relationship. As mentioned above, prior studies suggested that it is possible for social influence to affect usage in two ways: directly through compliance, or indirectly through its effect on beliefs (such as PU) and
AT due to internalization and identification processes (Karahanna and Straub, 1999). The "compliance" here is closely related to the level of voluntariness. Users have to "comply" with the managerial or organizational demands or rules in a mandatory, but not in a voluntary, context. That is to say, compliance means a direct influence of SN on BI and usually exists in mandatory contexts. Based on these arguments, Venkatesh and Davis considered the voluntary context as the reason for the insignificant $\mathrm{SN} \rightarrow$ BI relationship existing in prior studies. They then retested the role of voluntariness, especially its influence on the $\mathrm{SN} \rightarrow \mathrm{BI}$ relationship (Venkatesh and Davis, 2000). Their studies confirmed that SN had a significant direct effect on intentions for the mandatory but not for the voluntary usage context, and therefore voluntariness was considered 
as a moderating factor of $\mathrm{SN} \rightarrow \mathrm{BI}$ relationship (Venkatesh and Davis, 2000). Venkatesh et al. (2003) retested and confirmed this influence again in their latest work. Therefore, we propose the following:

P1-1. The influence of $S N$ on BI is stronger in mandatory contexts than in voluntary contexts.

Furthermore, Karahanna and Straub (1999) argued that the influence of "compliance" might become insignificant over time. In Venkatesh and Davis's (2000) research, the influence of the SN became smaller over time in both the studies in the mandatory context, which might imply that along with internalization, the effect of mandatory contexts might become smaller. That is to say, users may depend more on their own beliefs (through internalization), rather than others' opinions. Venkatesh et al. (2003) empirically found the same results. So we propose that:

P1-2. The moderating effects of voluntariness wear off over time.

It is noteworthy that many prior studies considered the accumulated experience as the reason for the insignificant influence of SN on intentions as proposed above. Thus, it is still uncertain that over time which of the two factors (accumulated experience or the smaller compliance) accounts for the insignificant relationship between SN and user acceptance. More empirical evidence is required.

\subsubsection{The nature of tasks and professions}

A variety of dimensions of tasks have been proposed (Goodhue, 1995), among which the most commonly used ones are routine vs. non-routine tasks, and tasks interdependent on other organizational tasks. Goodhue and Thompson (1995) suggested this dimension by conceptualizing and combining two previously defined characteristics of task, variety and difficulty (Goodhue, 1995). The authors hypothesized and subsequently empirically confirmed the effects of this dimension on user evaluation of technology. They argued that users who usually deal with a great variety of issues (non-routine) or ad hoc tasks would need to acquire new types of information from existing technology, and therefore were more likely to be frustrated by frequently identifying unfamiliar data and determining how to access and interpret it (Goodhue, 1995). With the limited cognitive capacity a user has, the demand of dealing with non-routine tasks can be high and would leave less capacity to deal with the challenges faced with using the system. Thus, high PEOU would be very important for the user to accept the system. On the other hand, ease with routine tasks may provide a user with more capacity to deal with using the system, thus a low PEOU would be less overwhelming. Thus, we propose that:

P1-3. PEOU has more influence on BI for users dealing with non-routine tasks than for those dealing with routine tasks.

Another dimension is interdependence of tasks. Users engaged in tasks that are interdependent with other organizational units will need to identify, access and integrate data from a variety of systems, and they are more likely to be frustrated by the incompatibilities in data and access routines for these systems, and overall by the high cognitive demand (Goodhue, 1995). The "wearing off" effects of PEOU seem weaker for them.

Similarly, Chau and $\mathrm{Hu}$ (2002, p. 213) also argued that a high level of autonomy might cause limited impacts of PEOU. Some professions require collaboration and others may require professional autonomy. This dimension may influence the effects of social influence (SNs). For example, Chau and $\mathrm{Hu}$ (2002) attributed insignificant peer influence to the personal autonomy of the physicians used in their study. They argued that "specialized training and high autonomy encourage independent thinking and decisionmaking, which may jointly contribute to a physician's tendency to respect but place relatively less weight on peers' opinions in AT development or making a technology acceptance decision" (Chau and Hu, 2002, p. 214). Therefore,

P1-4. The impact of PEOU on BI is weaker for highly independent tasks/professions than for less independent tasks/professions.

P1-5. The impact of $S N$ on BI is weaker for highly independent tasks/professions than for less independent tasks/professions.

\subsection{Propositions for technological moderators}

Most of the studies used common technologies, such as email, v-mail, word processing software and spreadsheets, while others used specific technologies, such as customer dial-up systems (Subramanian, 1994), database management systems (DBMSs) (Szajna, 1994), managerial systems (Venkatesh and Davis, 2000), telemedicine technology (Chau and $\mathrm{Hu}, 2002$ ) and information retrieval systems (Venkatesh and Morris, 2000).

Few previous studies focused on the effects of different technologies. However, based on our analysis, the main relationships may differ across technologies. For example, Adams et al. (1992) studied two groups of technologies and found different relationships of user acceptance constructs. Based on the analysis of the collected articles, we try to identify the following technological moderating factors.

\subsubsection{Technological complexity}

One dimension of technology is complexity. Subramanian (1994) attributed the insignificant effects of PEOU on BI to the nature of the systems in the study. The author argued that one reason for the insignificant effect of PEOU was that both v-mail and customer dial-up systems used in the study were communication technologies that are much easier to use than software packages such as Harvard Graphics and spreadsheets (Subramanian, 1994). Similarly, 
Teo et al. (1999) attributed the insignificant effects of PEOU on BI to the simplicity of the technology used in their study, the Internet. The authors argued that since the Internet was relatively easy to use, the learning process, in which PEOU was confirmed to have significant influence on BI, was quickly completed. Therefore, we propose that:

P2-1. The influence of PEOU on BI is stronger for technologies that are more complex.

P2-2. The influence of PEOU on $P U$ is stronger for technologies that are more complex.

\subsubsection{The purpose of using technology: work-oriented vs. entertainment-oriented}

Some researchers noted that the purpose of using technology could have different impacts on user acceptance. For example, Lederer et al. (2000) listed that one of the limitations of their studies was the assumption that the technology in question was used in work places and different from technologies for games or chatting. Similarly, Moon and Kim (2001) compared two groups of users viewing WWW as work-oriented and entertainmentoriented, respectively. They confirmed empirically that PU has a more significant effect for users who use the Internet as work-oriented technology than for those using the Internet as entertainment-oriented technology. Using similar logic, Amoako-Gyampah and Salam (2003) conducted a study on ERP implementation environment and found an insignificant effect of PEOU. Then they attributed the insignificant effect of PEOU to the fact that ERP users are more concerned with the larger goal of how an ERP system supports business processes, implying that technologies like ERP systems are so work-oriented that they will be used no matter whether they are easy to use or not. More recently, Heijden (2004) studied user acceptance of hedonic systems, which provide self-fulfilling value to the user, in contrast to utilitarian systems, which aim to provide instrumental value to the user. They found that PEOU is a stronger determinant of intention to use a hedonic IS than PU. Based on the above discussions, we propose that:

P2-3. PU has more influence on BI for work-oriented technologies than for entertainment-oriented technologies.

P2-4. PEOU has less influence on BI for work-oriented technologies than for entertainment-oriented technologies.

\subsubsection{Individual vs. group technologies}

Both individual and group technologies have been investigated in prior studies (Table 3). Unlike individual technology, which aims to improve individual productivity, group technology (groupware) aims to facilitate group coordination and to support cooperation and collaboration among a group of users. User acceptance of group- ware is therefore different from that of individual technology due to the unique features of groupware (Lou et al., 2000). SN's effects may be different for individual technologies such as word processing software and group technologies such as email or v-mail. For example, Davis et al. (1989) argued that the lack of a significant $\mathrm{SN} \rightarrow \mathrm{BI}$ effect might be due to the technology used in the study. They argued that word processing was fairly personal and individual and may be driven less by social influences compared to other technologies such as email, project management or group decision support systems, and therefore, SN may have less effect in such technological contexts (Davis et al., 1989). Users who have adopted the technology have the incentive to enlist more users for the technology, and they may be eager to promote the technology by sharing their experience with and offering help to potential adopters (Lou et al., 2000). Such unsolicited help from many peers due to the unique features of groupware may convince a potential user that it would not take a lot of time and effort to learn and use the groupware, which promotes their intention to use it. Based on the above discussion, we propose that:

P2-5. SN has more influence on BI for group technologies than for individual technologies.

P2-6. SN has more influence on PU for group technologies than for individual technologies.

\subsection{Propositions for individual moderators}

Individual differences are usually user factors that include demographic variables and situational variables that account for differences attributable to circumstances such as experience and training (Agarwal and Prasad, 1999b). Many technology acceptance studies neglect moderating effects of individual factors, although some do admit that the absence of such characteristics is one of their work's limitations (e.g., Davis et al., 1989). The inconsistencies existing in prior studies imply that perceptions are not equally efficacious in developing usage intentions for everyone (Venkatesh, 2000). The TRA, e.g., indirectly acknowledges such individual differences by asking potential users to assess the importance of each belief (Agarwal and Prasad, 1998).

Review of the articles yields the following individual factors that may have moderating effects: (1) gender; (2) intellectual capabilities; (3) experience; (4) age and (5) cultural background. Next we will discuss each factor in detail.

\subsubsection{Gender}

Gender has been generally missing from IT behavioral research (Gefen and Straub, 1997). Nonetheless, research has shown that decision-making processes by woman and men are different (Venkatesh and Morris, 2000). Studies 
suggested that women and men are different in terms of information processing, using different socially constructed cognitive structures (Venkatesh and Morris, 2000). For example, female and male are different in characteristics they consider important in evaluating products and processing strategies used at recognition of advertisements (Meyers-Levy and Maheswaran, 1991). Gender differences also occur across cultures (Gefen and Straub, 1997).

Three major gender differences are critical for user acceptance research. First, men are more "pragmatic" than women. Compared to women, men are more task-oriented (Minton and Schneider, 1980) and motivated by achievement needs (Hoffman, 1972). This is directly related to usefulness perception. Second, compared to men, women have higher computer anxiety and lower computer self-efficacy. This difference is closely related to PEOU in that higher computer self-efficacy leads to lowering of ease of use perception (Venkatesh and Morris, 2000). Third, women have a greater awareness of others' feelings compared to men, and are therefore more likely to be influenced by others (Venkatesh and Morris, 2000). This difference is directly related to the influence of SNs.

Correspondingly, in their research, Venkatesh and Morris (2000) argued that men are more driven by PU, while women are more motivated by PEOU and SN. The influence of PU on BI $(\beta)$ was $0.61,0.62$ and 0.62 at three points of measurement for men and $0.30,0.32$ and 0.36 for women. Therefore, men and women are significantly different in terms of $\mathrm{PU} \rightarrow \mathrm{BI}$ relationship. As for the effects of PEOU on BI, this study also confirmed that women were more influenced by ease of use than men, with $\beta$ values of $0.33,0.31$ and 0.36 for women and $0.10,0.01$ and 0.05 for men, respectively. They also argued that the PEOU $\rightarrow$ PU relationship is identical for male and female both pre- and post-usage (with accumulated experience). Furthermore, SN had no effect on men's decisions at any point in time, while it did matter for women at the initial stage of technology introduction.

Gefen and Straub (1997) also made some arguments about the importance of SNs for women, indicating that "women would use e-mail for more interactive exchanges and more context building exchanges than men would because of feminine discourse tendencies to use communication for rapport and cooperative behavior".

Similarly, Venkatesh et al. (2003) argued that gender might moderate the relationship between (1) PU and BI; (2) PEOU and BI; and (3) SN and BI. After including gender as a moderator, the explanatory power of TAM significantly increased to $52 \%$.

These findings suggest that gender moderates the effects of $\mathrm{PU} \rightarrow \mathrm{BI}$, PEOU $\rightarrow \mathrm{BI}$ and $\mathrm{SN} \rightarrow \mathrm{BI}$. Therefore, we propose the following propositions.

P3-1. The effects of PU on BI are stronger for males than for females.
P3-2. The effects of PEOU on BI are stronger for females than for males.

P3-3. The effects of $S N$ on BI are stronger for females than for males.

\subsubsection{Individual intellectual capabilities}

The individual competence factor has received some attention in prior studies. For example, Lederer et al. (2000) noticed their subjects were "educated" and called for research on "less educated" users, which might have "provided additional validation of TAM and interesting insights about ease of use and usefulness".

A related concept is "profession". Many prior studies have explored the role of profession and considered it an explicit indicator of a user's general competence and mental/cognitive capacities (e.g., Chau and $\mathrm{Hu}, 2002$ ). The majority of prior studies use general people as research subjects. Existing models, however, may not succeed in demonstrating consistency across professions. For example, Hu et al. (1999, p. 106) argued that "TAM may not be appropriate for user populations that have considerably above-average general competence and intellectual capacity". In their study, PEOU had no significant influence on usefulness and BI for physicians. As for the SU-BI relationship, individual capacities may also moderate the SN's influence on user acceptance. Chau and $\mathrm{Hu}$ (2001) argued that the insignificant effects of $\mathrm{SN}$ on $\mathrm{BI}$ in their study were due to the professional nature of the samples, physicians in hospitals who had higher intellectual capacity. Dishaw and Strong (1999), however, argued that the professions might not account for the insignificant effect of $\mathrm{SN}$ on BI, since they used professionals in their study and got results similar to the ones using students as subjects. We consider the conflicting results to be due to the usage of explicit indicators rather than latent variables. That is to say, professions are just the explicit indicator. What really matters is the latent variable, one's general competence and intellectual capacity, such as learning ability. If prior results about the effects of professions were re-interpreted, the professionals would have higher competence and mental/cognitive capacities, and subsequently would have different beliefs or perceptions about a specific technology.

Many similar concepts have been identified, of which absorptive capacity is closely related to intellectual capability. Absorptive capacity is defined as the ability to recognize the value of new external knowledge, assimilate it, and apply it to commercial ends (Cohen and Levinthal, 1990). It is a multidimensional concept and can be applied at different levels. At the level of the individual, absorptive capacity refers to memory development, in which accumulated prior knowledge enables the ability to store new knowledge into one's memory and to recall and use it (Cohen and Levinthal, 1990). An important underpinning of absorptive capacity is that prior knowledge can facilitate the absorption of new knowledge. On the other hand, 
"knowledge diversity also facilitates the innovative process by enabling the individual to make novel associations and linkages" (Cohen and Levinthal, 1990, p. 131).

Thus, we propose the following propositions.

P3-4. The effects of PU on BI are stronger for those whose have stronger intellectual capacities.

P3-5. The effects of PEOU on BI are stronger for those whose have weaker intellectual capacities.

P3-6. The effects of $S N$ on BI are stronger for those whose have weaker intellectual capacities.

\subsubsection{Experience}

Measurements of experience vary in previous research. Experience is measured by the number of years a user has with computers in general (i.e., Venkatesh and Morris, 2000) and a dummy variable that employs ordinal values (i.e., $0,1,2$ ) to capture the increasing levels of user experience with the technology (i.e., Venkatesh et al., 2003). In longitudinal studies, experience is implied in the separation of stages, i.e., pre- and post-implementation (Szajna, 1996), or $1 \mathrm{~h}$ after introduction (Time 1) and 14 weeks after introduction (Time 2) (Davis et al., 1989). No specific definition of experience has been provided to date. Considering the key role of experience in understanding the belief-intention-acceptance relationship, researchers might use more finely grained of detail in its conceptualization of experience. Domain specific conceptualization of experience should be addressed.

Although in measurement, the concept of experience in previous studies refers to the same implied meaning: more familiar with and more knowledgeable about the technology of interest. Users may employ the knowledge gained from their prior experience to form their intentions (Fishbein and Ajzen, 1975). Generally speaking, existing models work well for both experienced and inexperienced users. However, prior studies confirmed that the effects of PU, PEOU and SN on BI differ between experienced and inexperienced users. Several prior studies suggested that experience influences relationships between (1) BI and Usage, (2) PU and BI, (3) PEOU and AT (Taylor and Todd, 1995a) and (4) SN and PU (Venkatesh and Davis, 2000; Venkatesh et al., 2003).

In general, PU remains a significant determinant of BI over time (Davis et al., 1989; Venkatesh and Davis, 2000; Venkatesh and Morris, 2000). Venkatesh et al. (2003) did not find a significant moderating effect of experience on "performance expectancy" that was similar to PU in TAM, either. The moderating effect of experience on PEOU $\rightarrow \mathrm{BI}$ relationship is clear and stable. We can refer to knowledge diversity as mentioned in the last subsection. A diverse knowledge background provides a more robust basis for learning because it increases the prospect that incoming information will relate to what is already known (Cohen and Levinthal, 1990). Similarly, when users have more knowledge gained through prior experience with similar technologies, they have more knowledge sources when learning the new IT, and therefore may perceive that ease of use is not a big issue. Almost all the prior studies that studied the moderating effects of experience confirmed that the effect of PEOU on either PU or BI wore off over time (Davis et al., 1989; Adams et al., 1992; Taylor and Todd, 1995a; Venkatesh et al., 2003). Taylor and Todd (1995a) empirically confirmed that $\mathrm{BI} \rightarrow$ Usage is more significant for experienced users than for inexperience users. This is easy to understand since experienced users utilize their prior experience to form their intentions (Fishbein and Ajzen, 1975).

Therefore, we propose that:

P3-7. PEOU has less influence on BI for experienced users than for inexperienced users.

P3-8. PEOU has less influence on PU for experienced users than for inexperienced users.

P3-9. BI has more influence on actual usage for experienced users than for inexperienced users.

As for the SN, experience also moderates its influences on BI and PU. Venkatesh and Davis confirmed that influence of SN on either BI or PU attenuated over time. Users may use their direct experience with a system rather than others' opinions to form their intentions and perceptions of usefulness (Venkatesh and Davis, 2000). In another study, Venkatesh and Morris (2000) found similar effects. While SN did not have significant effects for men at any time, it did have significant influence on intention for women. But the effects became weaker over time. Similarly, Karahanna and Straub (1999) argued that potential adopters (inexperienced) are influenced by SNs more than current users (experienced). Based on their findings, we propose that:

P3-10. SN has less influence on BI for experienced users than for inexperienced users.

P3-11. $S N$ has less influence on $P U$ for experienced users than for inexperienced users.

It is noteworthy that prior researchers also found another similar concept, computer literacy. Chau (1996b) argued that PEOU has no significant influence because users are "generally more computer-literate than their counterparts five to ten years ago" and subsequently "ease of use may have been less of an issue for this sample than it would have been for the samples used in prior studies". More specifically, along with the interaction with information technologies, users may in general 
have more computer self-efficacy (Compeau et al., 1999). The higher the computer self-efficacy, the less the users depend on ease of use (Venkatesh and Morris, 2000). Compared with the experience with specific systems, computer literacy is more like a user's "trait", which is more general and stable. In simple terms, then, we can see computer literacy as an "indirect" experience in conjunction with general information technology, which has effects similar to "direct" experience with specific technologies. Therefore, we propose that computer literacy, while different from experience, has moderating effects similar to those of experience.

\subsubsection{Age}

Compared with other potential moderating factors such as experience, age received less attention in prior studies. Venkatesh et al. (2003) found young users placed more importance on extrinsic reward (equivalent to PU). Similarly, Morris and Venkatesh (2002) found the same moderating effects of age. In addition, "increased age has been shown to be associated with difficulty in processing complex stimuli and allocating attention to information on the job" (Venkatesh et al., 2003, p. 450), implying that PEOU is a stronger determinant of BI for old users. Because affiliation needs increase with age, it may be that older users are more influenced by social factors (Venkatesh et al., 2003). Psychological research suggests that older workers are more likely to conform to others' opinions and have a relatively lower need for autonomy than younger workers (Evans et al., 1979; Cook and Wall, 1980). We thus propose that:

P3-12. PU has stronger influence on BI for younger users than for older users.

P3-13. PEOU has less influence on BI for younger users than for older users.

P3-14. SN has less influence on BI for younger users than for older users.

P3-15. SN has less influence on PU for younger users than for older users.

\subsubsection{Cultural background}

Another factor given relatively little attention was cultural background. Most research used North Americans as subjects. However, the social and cultural characteristics of European institutions can be studied as distinct from, or perhaps in contrast to, North American or Japanese institutions (Liebenau and Smithson, 1991). Thus, the applicability of research conducted in US universities and companies to businesses in other countries may be challenged (Igbaria et al., 1995).
Along with the increasing pace of globalization, the importance of understanding cultural influence is critical.

A widely used definition of culture is provided by Hofstede (1980). Culture is defined as "the collective programming of the mind which distinguishes the members of one group or category of people from another" (Hofstede, 1980, p. 5). Culture is a construct that is not directly accessible to observation but inferable from verbal statements and other behaviors, and useful in predicting other observable and measurable verbal and non-verbal behavior (Hofstede, 1993).

Several dimensions have been proposed (i.e., Hall and Hall, 1990; Hampden-Turner and Trompenaars, 1994; Lessem and Neubauer, 1994; Chen, 1995; Cragg, 1995). ${ }^{1}$ Among these dimensions, Hofstede's dimensions are widely used in the field of IS. Four dimensions are suggested including power distance, individualism/collectivism, masculinity/femininity and uncertainty avoidance (Hofstede, 1980).

Power distance is defined as the degree of inequality among people which the population of a country considers as normal: from relatively equal (i.e., small power distance) to extremely unequal (large power distance) (Hofstede, 1993). In a society in which people are separated by a large power distance, the leveling effects of certain technologies (i.e., communication technologies) are not desirable. Instead, they may choose media with high social presence such as face-to-face interaction (Straub et al., 1997). In high power distance culture, individuals are not supposed to disagree with their superiors. Subsequently, they are more likely to rely on others' opinions to form their decisions. Based on the discussions above, we propose:

P3-16. $P U$ has less influence on BI for individuals in high power distance cultures.

P3-17. SN has more influence on BI for individuals in high power distance cultures.

Individualism is defined as the degree to which people in a country prefer to act as individuals rather than as members of groups (Hofstede, 1993). The opposite of individualism is collectivism. In collectivist societies people learn to respect the group to which they belong. According to the social presence theory (Short et al., 1976), people in a low individualism society may be against certain technologies such as communication technologies (i.e., email, v-mail) since they mute the group effects (Straub et al., 1997). Instead, they may choose a medium of high social presence such as face-toface communication. Therefore, they may perceive such technologies as less useful. On the other hand, it is logical to expect that in a low individualism (high

\footnotetext{
${ }^{1}$ For a comprehensive review, please refer to Myer and Tan (2002).
} 
collectivism) culture, people are more likely to consider other people's opinions. We thus propose:

P3-18. PU has more influence on BI for users in high individualism cultures.

P3-19. $S N$ has less influence on BI for users in high individualism cultures.

The third dimension is masculinity, which is defined as the degree to which tough values like assertiveness, performance, success and competition, which in nearly all societies are associated with the role of men, prevail over tender values like the quality of life, maintaining warm personal relationships, service, care for the weak and solidarity, which in nearly all societies are more associated with women's roles (Hofstede, 1993). Based on its definition, masculinity/femininity is closely related to interpersonal relationships. In a society with low masculinity (high femininity), a communicator such as email or vmail that cannot convey rich social presence may not be preferred and subsequently is considered less useful (Straub et al., 1997). In a high masculinity culture, people are more goal-oriented and the absence of social presence is not a problem. Instead, the effectiveness and efficiency conveyed in new technologies are preferred. On the other hand, in a femininity culture, individuals are more people-oriented and therefore they pay more attention to others' opinions. Therefore, we argue that:

P3-20. PU has more influence on BI for users in masculinity cultures.

P3-21. SN has less influence on BI for users in masculinity cultures.

Uncertainty avoidance is defined as the degree to which people in a culture prefer structured over unstructured situations (Hofstede, 1993). Structured situations are those in which there are clear rules as to how one should behave (Hofstede, 1993). According to information rich theory (Daft and Lengel, 1984), individuals choose media by matching the information requirements of the task to the information richness of the media (Straub et al., 1997). In societies with high uncertainty avoidance, individuals have higher needs for the richness of technology. Therefore, when other factors are controlled, individuals in such societies are more likely to perceive the technology as less useful. Instead, they would rather use a medium of higher information richness under the same circumstances. On the other hand, individuals in societies with high uncertainty avoidance are more likely to listen to others' opinion in order to reduce the uncertainty. Therefore, we propose that:

P3-22. PU has less influence on BI for users in a high uncertainty avoidance culture.

P3-23. $S N$ has more influence on BI for users in a high uncertainty avoidance culture.

\subsection{Summary}

Table 7 summarizes all the moderators and their effects. An examination of Table 7 gives us several interesting findings. First, if we examine the table vertically, all the linkages in the model are more or less subject to the influence of moderating factors, which means moderating factors have profound effects on user technology acceptance. On the one hand, some linkages such as $\mathrm{SN} \rightarrow \mathrm{BI}$ and PEOU $\rightarrow \mathrm{BI}$ are influenced by almost all moderating factors. On the other hand, we can see that the $\mathrm{BI} \rightarrow$ Usage link is influenced by just one moderating factor. It may imply that this relationship is very robust and valid across situations, which is consistent with prior studies. Second, if we examine the table horizontally, some factors, such as experience and age, seem to have more effects on user technology acceptance than other factors do. For instance, experience influences all the relationships in the model. Third, we can also observe the interactions among moderating factors. For example, P1-2 suggests that the moderating influence of voluntariness wears off along with accumulated user experience. It implies the interaction between voluntariness and experience. On the whole, Table 7 suggests that moderating factors influence most of the relationships and therefore should be considered when studying user technology acceptance.

\section{Conclusions}

Although they have received considerable empirical validation and confirmation, existing user acceptance models still have room for improvement. Their limited explanatory power and inconsistent relationships call for taking additional factors into account. Researchers have suggested models be tested in field settings with organizational and technological factors considered (Lucas and Spitler, 1999; e.g., Sun and Zhang, 2004). This present study is an attempt to move in this direction. By including the moderators in user acceptance models, we hope to lessen the limitations of low explanatory power and inconsistencies existing in prior studies. It is noteworthy that the influence of including moderating factors on $R^{2}$ is statistically limited (Chin et al., 2003). However, by taking moderating factors into account, we are more confident in explaining and describing the meanings of existing models.

This paper draws several implications for both researchers. First, this study suggests that research on moderating factors is of great value. This is consistent with suggestions from existing studies that contexts could play an important role in user technology acceptance (Davis et al., 1989; Taylor and Todd, 1995a; Szajna, 1996). It is noteworthy that the major function of moderating factors is explaining the inconsistencies by identifying the situational differences. Its effect in enhancing $R^{2}$ is modest. This observation is consistent with prior empirical study (Chin et al., 2003). 


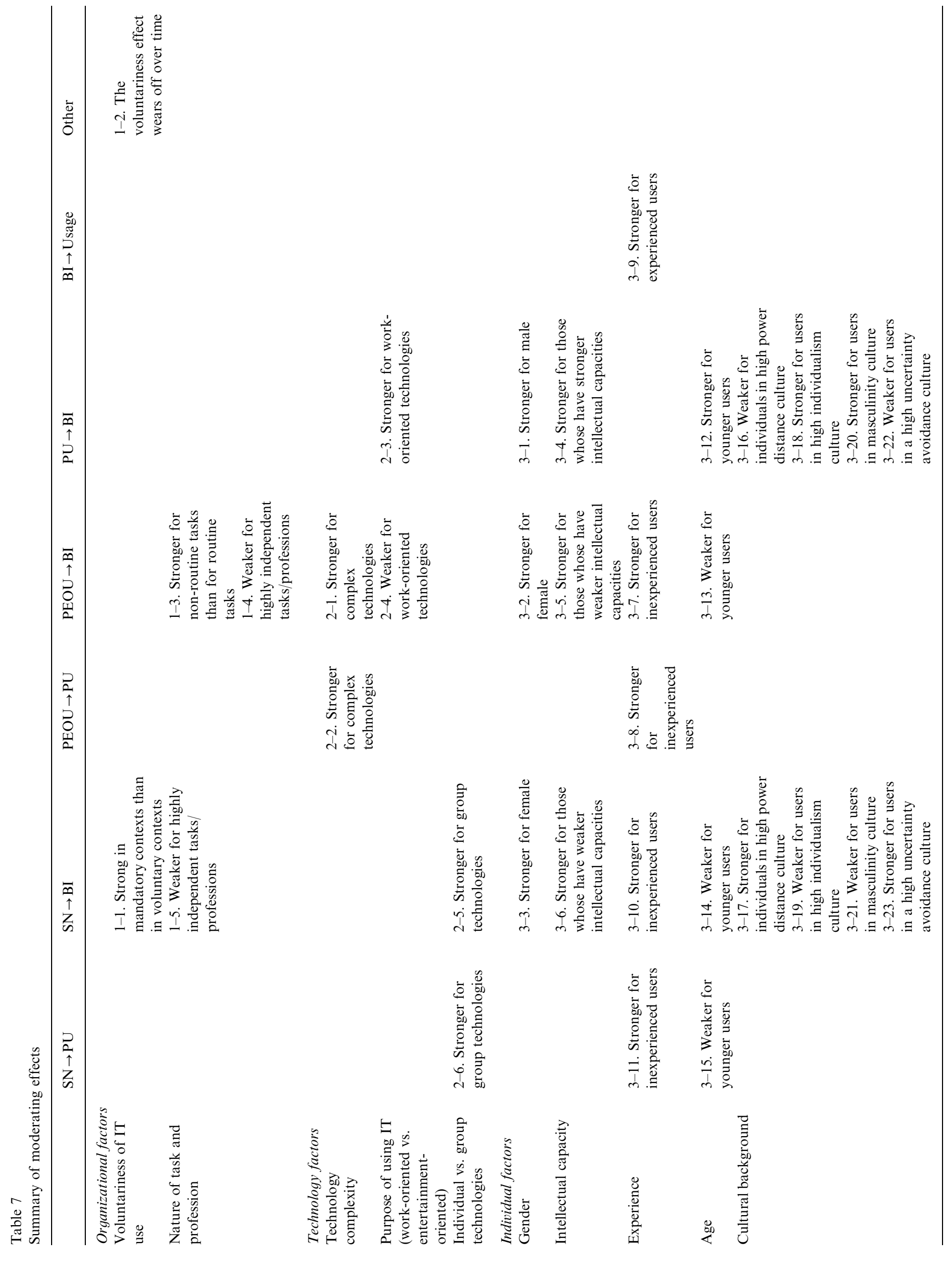


Second, research should pay more attention to less studied issues. For instance, few studies have empirically examined cultural issues associated with user technology acceptance. The mechanisms through which the culture exerts its influence are still unclear (e.g., Straub et al., 1997). Therefore, future research may focus on "how" questions by identifying the major cultural dimensions and their corresponding relationships with user technology acceptance.

Third, compared to the moderating effects of individual factors, those effects of organizational factors such as the nature of tasks, and technological factors such as technology complexity, have not received sufficient attention so far and thus leave room for further investigation.

We should also notice the interactions among these moderating factors. We cannot simply say that women always pay attention to the influence of SNs. For women who have a lot of experience with the technology of interest, it may not be true. Therefore, we should consider all the major moderating factors simultaneously. It is, however, too early to reach any conclusions about which effects are more robust. More empirical tests are needed to address the interactions among these moderating factors.

Finally, from a methodological perspective, studies of user acceptance may need a methodological shift in order to gain richer understanding of less studied factors. So far, almost all the prior studies use quantitative research methodology and usually from a positivist perspective. Qualitative methodology, especially from an interpretive perspective, however, is informative and may be another useful alternative that can give researchers new insights (Lee et al., 2003). Among these methodologies, a good example is grounded theory (Glaser and Strauss, 1967), which allows a focus on contextual and process elements as well as the action of key players (users) associated with contextual change (Orlikowski, 1993). Although successfully used in IS in general, these methodologies, such as grounded theory, are rarely used in research on user technology acceptance. In addition, the nature of user technology acceptance calls for periodic examinations of the determining factors along with the development of information technology. New technologies often involve factors that have rarely been considered before. For example, trust, which is not a traditionally considered factor, may influence users' intentions to use on-line shopping (Gefen et al., 2003) or mobile commerce (Siau et al., 2003). These methodological perspectives can help us identify the potential factors inductively.

For practitioners, this research also has several implications in that the findings and propositions can be easily translated into practice. First, practitioners should pay particular attention to the inclusion of individual and contextual factors when using these models to predict user acceptance of technologies. Practitioners should realize that existing models are conditional and therefore simply provide a basis for understanding user technology accep- tance. To predict user acceptance of a specific system, individual and contextual factors should be taken into account.

Second, the findings have implications for designing training programs. Training programs should highlight the influence of individual and contextual factors. For example, for men, the training program should emphasize usefulness; while for women, ease of use and SNs (such as peer influence) should be emphasized. Further, trainers should pay attention to the evolution of trainees' perceptions and the influence of SNs. Specifically, in the early stage of the system use, ease of use and $\mathrm{SN}$ is more important, especially for women. Therefore, trainers can develop specific tactics such as focusing on how to use the system and encouraging communication among female users Realizing that once users are no longer newcomers to the system, and thus focusing on usefulness, the training program should accordingly focus on usefulness, exploring the functional potentials of the system of interest. This strategy can also be applied for users with different levels of prior experience. Other potential factors include voluntariness, the nature of the tasks and the professions, and technological factors as suggested earlier in the paper. By taking these factors into account, practitioners can take corresponding measures to predict or promote user technology acceptance more effectively and efficiently.

There are some limitations in this study. One is the limited number of articles reviewed. Even though they are considered representative, only 54 articles are included in this study. The results, therefore, could be biased to some extent. On the bright side, our results show great consistency with several other meta-analysis results (Lee et al., 2003; Legris et al., 2003; Ma and Liu, 2004). The second limitation is that the relationships between moderating factors are not under consideration and therefore the proposed model may need further refinement. For example, Chau and $\mathrm{Hu}$ (2002) argued that the subjects used in their research, physicians, had more "power of expertise", and more autonomy over their work, and therefore were less likely to be influenced by "administrative and managerial decisions", which were usually mandatory. Their arguments suggest a relationship between two moderators, voluntariness and profession autonomy. The research on interactions among factors and relationships within the integrated model can add more practical values to the model by finding more explicit factors that are easy to use. These limitations will be addressed in future research.

It is noteworthy that we realize a balance between a comprehensive and a barebones model. The inclusion of moderating factors is assumed to enhance explanatory power while lowering the model's elegance. In this study, we emphasize enhancing explanatory power, while leaving parsimony to future research, since low explanatory power seems more salient to date (Lee et al., 2003). 


\section{Appendix A. The articles used in the meta analysis}

\begin{tabular}{|c|c|c|c|}
\hline Article ID & Title & Journal & Page \\
\hline Davis et al. (1989) & $\begin{array}{l}\text { User acceptance of computer technology: a } \\
\text { comparison of two theoretical models }\end{array}$ & $\begin{array}{l}\text { Management Science } \\
(35: 8)\end{array}$ & \\
\hline \multicolumn{4}{|l|}{$982-1003$} \\
\hline Davis (1989) & $\begin{array}{l}\text { Perceived usefulness, perceived ease of use, and } \\
\text { user acceptance of information technology }\end{array}$ & MIS Quarterly (13:3) & $319-340$ \\
\hline $\begin{array}{l}\text { Thompson et al. } \\
\text { (1991) }\end{array}$ & $\begin{array}{l}\text { Personal computing toward a conceptual model } \\
\text { of utilization }\end{array}$ & MIS Quarterly (15:1) & $125-143$ \\
\hline Mathieson (1991) & $\begin{array}{l}\text { User intentions: comparing the technology } \\
\text { acceptance model with the theory of planned } \\
\text { behavior }\end{array}$ & $\begin{array}{l}\text { Information Systems } \\
\text { Research (2) }\end{array}$ & $173-191$ \\
\hline Adams et al. (1992) & $\begin{array}{l}\text { Perceived usefulness, ease of use and usage of } \\
\text { information technology: a replication }\end{array}$ & MIS Quarterly (16:2) & $227-250$ \\
\hline Davis et al. (1992) & $\begin{array}{l}\text { Extrinsic and intrinsic motivation to use } \\
\text { computers in the workplace }\end{array}$ & $\begin{array}{l}\text { Journal of Applied Social } \\
\text { Psychology (22) }\end{array}$ & \\
\hline \multicolumn{4}{|l|}{$1111-1132$} \\
\hline Davis (1993) & $\begin{array}{l}\text { User acceptance of information technology: } \\
\text { system characteristics, user perceptions and } \\
\text { behavioral impacts }\end{array}$ & $\begin{array}{l}\text { International Journal of } \\
\text { Man-Machine Studies (38) }\end{array}$ & $475-487$ \\
\hline $\begin{array}{l}\text { Hendrickson et al. } \\
\text { (1993) }\end{array}$ & $\begin{array}{l}\text { On the test-retest reliability of perceived } \\
\text { usefulness and perceived ease of use scales }\end{array}$ & MIS Quarterly (17:2) & $227-230$ \\
\hline $\begin{array}{l}\text { Segars and Grover } \\
(1993)\end{array}$ & $\begin{array}{l}\text { Re-examining perceived ease of use and } \\
\text { usefulness: a confirmatory factor analysis }\end{array}$ & MIS Quarterly (18:4) & $517-525$ \\
\hline $\begin{array}{l}\text { Barki and Hartwick } \\
\text { (1994) }\end{array}$ & $\begin{array}{l}\text { Measuring user participation, user involvement } \\
\text { and user attitude }\end{array}$ & MIS Quarterly (18:1) & $59-82$ \\
\hline Subramanian (1994) & $\begin{array}{l}\text { A replication of perceived usefulness and } \\
\text { perceived ease of use measurement }\end{array}$ & $\begin{array}{l}\text { Decision Sciences }(25:(5 / \\
\text { 6)) }\end{array}$ & $863-874$ \\
\hline Szajna (1994) & $\begin{array}{l}\text { Software evaluation and choice: predictive } \\
\text { validation of the technology acceptance } \\
\text { instrument }\end{array}$ & MIS Quarterly (18:3) & $319-324$ \\
\hline $\begin{array}{l}\text { Chin and Gopal } \\
(1995)\end{array}$ & $\begin{array}{l}\text { Adoption intention in GSS relative importance } \\
\text { of beliefs }\end{array}$ & Data Base $(26: 2 / 3)$ & $42-63$ \\
\hline $\begin{array}{l}\text { Chin and Todd } \\
\text { (1995) }\end{array}$ & $\begin{array}{l}\text { On the use, usefulness and ease of use of } \\
\text { structural equation modeling in MIS research: a } \\
\text { note of caution }\end{array}$ & MIS Quarterly (19:2) & $269-280$ \\
\hline $\begin{array}{l}\text { Taylor and Todd } \\
\text { (1995b) }\end{array}$ & $\begin{array}{l}\text { Understanding information technology usage: a } \\
\text { test of competing models }\end{array}$ & $\begin{array}{l}\text { Information Systems } \\
\text { Research }(6: 2)\end{array}$ & $144-172$ \\
\hline $\begin{array}{l}\text { Taylor and Todd } \\
\text { (1995a) }\end{array}$ & Assessing IT usage: the role of prior experience & MIS Quarterly (19:4) & $561-570$ \\
\hline Chau (1996a) & $\begin{array}{l}\text { Empirical assessment of a modified technology } \\
\text { acceptance model }\end{array}$ & $\begin{array}{l}\text { Journal of Management } \\
\text { Information Systems } \\
(13: 2)\end{array}$ & $185-204$ \\
\hline Chau (1996b) & $\begin{array}{l}\text { An empirical investigation on factors affecting } \\
\text { the acceptance of CASE by systems developers }\end{array}$ & $\begin{array}{l}\text { Information \& } \\
\text { Management (20) }\end{array}$ & $269-280$ \\
\hline $\begin{array}{l}\text { Davis and } \\
\text { Venkatesh (1996) }\end{array}$ & $\begin{array}{l}\text { A critical assessment of potential measurement } \\
\text { biases in the technology acceptance model: three } \\
\text { experiments }\end{array}$ & $\begin{array}{l}\text { International Journal of } \\
\text { Human-Computer } \\
\text { Studies }(45: 1)\end{array}$ & $19-45$ \\
\hline $\begin{array}{l}\text { Hendrickson and } \\
\text { Collins (1996) }\end{array}$ & $\begin{array}{l}\text { An assessment of structure and causation of IS } \\
\text { usage }\end{array}$ & Data Base (27:2) & $61-67$ \\
\hline Igbaria et al. (1996) & A motivational model of microcomputer usage & $\begin{array}{l}\text { Journal of Management } \\
\text { Information Systems } \\
(13: 1)\end{array}$ & $127-143$ \\
\hline Szajna (1996) & $\begin{array}{l}\text { Empirical evaluation of the revised technology } \\
\text { acceptance model }\end{array}$ & $\begin{array}{l}\text { Management Science } \\
(42: 1)\end{array}$ & $85-92$ \\
\hline
\end{tabular}


Venkatesh and

Davis (1996)

Gefen and Straub

(1997)

Igbaria et al. (1997)

Jackson et al. (1997)

Straub et al. (1997)

Doll et al. (1998)

Gefen and Keil

(1998)

Agarwal and Prasad (1999a)

Dishaw and Strong

(1999)

Hu et al. (1999)

Karahanna and

Straub (1999)

Karahanna et al. (1999)

Lucas and Spitler (1999)

Teo et al. (1999)

Agarwal and

Karahanna (2000)

Gefen and Straub

(2000)

Lederer et al. (2000)

Venkatesh (2000)

Venkatesh and

Davis (2000)

Venkatesh and

Morris (2000)

Bhattacherjee (2001)

Chau and $\mathrm{Hu}$ (2001)
A model of the antecedents of perceived ease of use: development and test

Gender differences in the perception and use of e-mail: an extension to the technology acceptance model

Personal computing acceptance factors in small firms: a structural equation model

Toward an understanding of the behavioral intention to use an information system

Testing the technology acceptance model across cultures: a three country study

Using Davis's perceived usefulness and ease-ofuse instruments for decision making: a

confirmatory and multigroup invariance analysis

The impact of developer responsiveness on perceptions of usefulness and ease of use: an extension of the technology acceptance model Are individual differences germane to the acceptance of new information technologies? Extending the technology acceptance model with task-technology fit constructs

Examining the technology acceptance model using physician acceptance of telemedicine technology

The psychological origins of perceived usefulness and ease-of-use

Information technology adoption across time: a cross-sectional comparison of pre-adoption and post-adoption beliefs

Technology use and performance: a field study of broker workstations

Intrinsic and extrinsic motivation in internet usage

Time flies when you're having fun cognitive absorption and beliefs about information technology usage

The relative importance of perceived ease of use in IS adoption: a study of E-commerce adoption

The technology acceptance model and World Wide Web

Determinants of perceived ease of use: integrating control, intrinsic motivation and emotion into the technology acceptance model A theoretical extension of the technology acceptance model: four longitudinal field studies Why don't men ever stop to ask for directions? gender, social influence and their role in technology acceptance and usage behavior Understanding information systems continuance: an expectation-confirmation model

Information technology acceptance by individual professionals: a model comparison approach
Decision Sciences (27:3)

$451-481$

MIS Quarterly (21:4)

$389-400$

MIS Quarterly (21:3)

279-301

Decision Science (28:2)

357-389

Information \&

Management (33:1)

Decision Science (29:4)

839-869

Data Base (29:2)

$35-49$

Decision Sciences 30(2)

361-391

Information \&

9-21

Management (36:1)

Journal of Management

$91-112$

Information Systems

$(16: 2)$

Information \&

Management (35)

MIS Quarterly (23:2)

$237-250$

183-213

Decision Sciences (30:2)

291-311

OMEGA International

$25-37$

Journal of Management

Science (27:1)

MIS Quarterly (24:4)

665-694

Journal of the Association

$1-28$

for Information Systems

(1)

Decision Support Systems

(29)

Information Systems

Research (11:4)

Management Science

(46:2)

MIS Quarterly (24:1)

186-204

115-139

MIS Quarterly (25:3)

351-370

Decision Sciences (32:4) 
Hong et al. (2001)

Moon and Kim

(2001)

Mathieson et al.

(2001)

Venkatesh and

Brown (2001)

Chau and $\mathrm{Hu}(2002)$

Chen et al. (2002)

Gefen et al. (2003)

Heijden (2003)

Venkatesh et al.

(2003)

Heijden (2004)
Determinants of user acceptance of digital libraries: an empirical examination of individual differences and system characteristics Extending the TAM for a World-Wide-Web context

Extending the technology acceptance model: the influence of perceived user resources

A longitudinal investigation of personal

computers in homes: adoption determinants and emerging challenges

Investigating professionals' decisions to accept telemedicine technology: an empirical test of competing theories

enticing online consumers: an extended technology acceptance perspective

Trust and TAM in online shopping: an integrated model

Factors influencing the usage of Websites: the case of a generic portal in the Netherlands User acceptance of information technology: toward a unified view User acceptance of hedonic information systems
Journal of Management

Information Systems

$(18: 3)$

Information \&

Management (38:4)

Data Base (32:3)

86-112

MIS Quarterly (25:1)

71-102

Information \&

297-311

Management (39)

Information \&

Management (39)

MIS Quarterly (27:1)

Information \&

Management (40)

MIS Quarterly (27:3)

425-478

MIS Quarterly (28:4)

\section{References}

Adams, D.A., Nelson, R.R., Todd, P.A., 1992. Perceived usefulness, ease of use, and usage of information technology: a replication. MIS Quarterly 16 (2), 227-247.

Agarwal, R., Karahanna, E., 2000. Time flies when you're having fun: cognitive absorption and beliefs about information technology usage. MIS Quarterly 24 (4), 665-694.

Agarwal, R., Prasad, J., 1998. The antecedents and consequents of user perceptions in information technology adoption. Decision Support Systems 22 (1), 15-29.

Agarwal, R., Prasad, J., 1999a. Are individual differences germane to the acceptance of new information technologies? Decision Sciences 30 (2), 361-391.

Agarwal, R., Prasad, J., 1999b. A conceptual and operational definition of personal innovativeness in the domain of information technology. Information Systems Research 9 (2), 204-215.

Amoako-Gyampah, K., Salam, A.F., 2003. An extension of the technology acceptance model in an ERP implementation environment. Information \& Management 41 (6), 731-745.

Barki, H., Hartwick, J., 1994. Measuring user participation, use involvement, and user attitude. MIS Quarterly 18 (1), 59-82.

Bhattacherjee, A., 2001. Understanding information systems continuance: an expectation-confirmation model. MIS Quarterly 25 (3), 351.

Chau, P.Y.K., 1996a. Empirical assessment of a modified technology acceptance model. Journal of Management Information Systems 13 (2), 185-204.

Chau, P.Y.K., 1996b. An empirical investigation on factors affecting the acceptance of CASE by systems developers. Information \& Management 30 (6), 269-280.

Chau, P.Y.K., Hu, P.J.H., 2001. Information technology acceptance by individual professionals: a model comparison approach. Decision Sciences 32 (4), 699-719.

Chau, P.Y.K., Hu, P.J.H., 2002. Investigating healthcare professionals' decisions to accept telemedicine technology: an empirical test of competing theories. Information \& Management 39 (4), 297-311.

Chen, L.D., Gillenson, M.L., Sherrell, D.L., 2002. Enticing online consumers: an extended technology acceptance perspective. Information \& Management 39 (8), 705-719.
Chen, M., 1995. Asian Management Systems. Routledge, London.

Chin, W.W., Gopal, A., 1995. Adoption intention in GSS: relative importance of beliefs. The Data Base for Advances in Information Systems 26 (2-3), 42-64.

Chin, W.W., Todd, P.A., 1995. On the use, usefulness, and ease of use of structural equation modeling in MIS research: a note of caution. MIS Quarterly 19 (2), 237.

Chin, W.W., Marcolin, B.L., Newsted, P.R., 2003. A partial least squares latent variable modeling approach for measuring interaction effects: results from a Monte Carlo simulation study and an electronic-mail emotion/adoption study. Information Systems Research 14 (2).

Cohen, W.M., Levinthal, D.A., 1990. Absorptive capacity: a new perspective on learning and innovation. Administrative Science Quarterly 35, 128-152.

Compeau, D.R., Higgins, C.A., 1995a. Application of social cognitive theory to training for computer skills. Information Systems Research 6 (2), 118-143.

Compeau, D.R., Higgins, C.A., 1995b. Computer self-efficacy: development of a measure and initial test. MIS Quarterly 19 (2), 189-211.

Compeau, D.R., Higgins, C.A., Huff, S., 1999. Social cognitive theory and individual reactions to computing technology: a longitudinal study. MIS Quarterly 23 (2), 145-158.

Cook, J., Wall, T., 1980. New work attitude measures of trust, organizational commitment and personal need nonfulfillment. Journal of Occupational Psychology 53 (39-52).

Cragg, C., 1995. The New Taipans. Century Business, London.

Daft, R.L., Lengel, R.H., 1984. Information richness: a new approach to managerial behavior and organizational design. Research in Organizational Behavior, 191-233.

Davis, F.D., 1989. Perceived usefulness, perceived ease of use, and user acceptance of information technology. MIS Quarterly 13 (3), 319-342.

Davis, F.D., 1993. User acceptance of information technology: system characteristics, user perceptions and behavioral impacts. International Journal of Man-Machine Studies 38 (3), 475-487.

Davis, F.D., Venkatesh, V., 1996. A critical assessment of potential measurement biases in the technology acceptance model: three experiments. International Journal of Human-Computer Studies 45 (1), 19-45. 
Davis, F.D., Bagozzi, R.P., Warshaw, P.R., 1989. User acceptance of computer technology: a comparison of two theoretical models. Management Science 35 (8), 982-1003.

Davis, F.D., Bagozzi, R.P., Warshaw, P.R., 1992. Extrinsic and intrinsic motivation to use computers in the workplace. Journal of Applied Social Psychology 22, 1111-1132.

Dishaw, M.T., Strong, D.M., 1999. Extending the technology acceptance model with task-technology fit constructs. Information \& Management, 9-21.

Doll, W.J., Hendrickson, A., Deng, X.D., 1998. Using Daviss perceived usefulness and ease-of-use instruments for decision-making: a confirmatory and multigroup invariance-analysis. Decision Sciences 29 (4), 839-869.

Evans, M., Kiggundu, M., Hourse, R., 1979. A partial test and extension of the job characteristics model of motivation. Organizational Behavior and Human Performance 24, 354-381.

Fishbein, M., Ajzen, I., 1975. Beliefs, Attitude, Intention and Behavior: an Introduction to Theory and Research. Addison-Wesley, Reading, MA.

Gefen, D., Keil, M., 1998. The impact of developer responsiveness on perceptions of usefulness and ease of use: an extension of the technology of the technology acceptance model. The Data Base for Advances in Information Systems, 35-49.

Gefen, D., Straub, D.W., 1997. Gender difference in the perception and use of E-Mail: an extension to the technology acceptance model. MIS Quarterly 21 (4), 389-400.

Gefen, D., Straub, D.W., 2000. The relative importance of perceived ease of use in IS adoption: a study of E-commerce adoption. Journal of the Association for Information Systems 1, 1-28.

Gefen, D., Karahanna, E., Straub, D.W., 2003. Trust and TAM in online shopping: an integrated model. MIS Quarterly 27 (1), 51-90.

Glaser, B.G., Strauss, A., 1967. The Discovery of Grounded Theory: Strategies for Qualitative Research. Aldine, Chicago, IL.

Goodhue, D.L., 1995. Understanding user evaluations of information systems. Management Science 41 (12), 1827-1844.

Goodhue, D.L., Thompson, R.L., 1995. Task-technology fit and individual performance. MIS Quarterly 19 (2), 213-236.

Hall, E.T., Hall, M.R., 1990. Understanding Cultural Differences. Intercultural Press, Yarmouth, ME.

Hampden-Turner, C., Trompenaars, F., 1994. The Seven Cultures of Capitalism. London.

Heijden, H.v.d., 2003. Factors influencing the usage of Websites - the case of a generic portal in the Netherlands. Information \& Management 40 (6), 541-549.

Heijden, H.v.d., 2004. User acceptance of hedonic information systems. MIS Quarterly 28 (4), 695-704.

Hendrickson, A.R., Collins, M.R., 1996. An assessment of structure and causation of IS usage. The Data Base for Advances in Information Systems 27 (2), 61-67.

Hendrickson, A.R., Massey, P.D., Cronan, T.P., 1993. On the test-retest reliability of perceived usefulness and perceived ease of use scales. MIS Quarterly 17 (2), 227-230.

Hoffman, L.W., 1972. Early childhood experiences and women's achievement motives. Journal of Social Issues 28 (2), 129-155.

Hofstede, G., 1980. Cultural Consequences: International Differences in Work Related Values. Sage, Beverly Hills.

Hofstede, G., 1993. Cultural constraints in management theories. The Academy of Management Executive 7 (1), 81-94.

Hong, W.Y., Thong, J.Y.L., Wong, W.M., Tam, K.Y., 2001. Determinants of user acceptance of digital libraries: an empirical examination of individual differences and system characteristics. Journal of Management Information Systems 18 (3), 97-124.

Hu, P.J., Chau, P.Y.K., Sheng, O.R.L., Tam, K.Y., 1999. Examining the technology acceptance model using physician acceptance of telemedicine technology. Journal of Management Information Systems, $91-112$.

Igbaria, M., Iivari, J., Maragahh, H., 1995. Why do individuals use computer technology? A Finnish case study. Information \& Management 29 (5), 227-238.
Igbaria, M., Parasuraman, S., Baroudi, J.J., 1996. A motivational model of microcomputer usage. Journal of Management Information Systems 13 (1), 127.

Igbaria, M., Zinatelli, N., Cragg, P., Cavaye, A.L.M., 1997. Personal computing acceptance factors in small firms: a structural equation model. MIS Quarterly 21 (3), 279-305.

Jackson, C.M., Chow, S., Leitch, R.A., 1997. Toward an understanding of the behavioral intention to use an information system. Decision Sciences 28 (2), 357-389.

Karahanna, E., Straub, D.W., 1999. The psychological origins of perceived usefulness and ease-of-use. Information \& Management 35 (3), 237-250.

Karahanna, E., Straub, D.W., Chervany, N., 1999. Information technology adoption across time: a cross-sectional comparison of preadoption and post-adoption beliefs. MIS Quarterly 23 (2), 183-213.

Lederer, A.L., Maupin, D.J., Sena, M.P., Zhuang, Y.L., 2000. The technology acceptance model and the World Wide Web. Decision Support Systems 29 (3), 269-282.

Lee, Y., Kozar, K.A., Larsen, K.R.T., 2003. The technology acceptance model: past, present, and future. Communications of the Association for Information Systems 12 (50), 752-780.

Legris, P., Ingham, J., Collerette, P., 2003. Why do people use information technology? A critical review of the technology acceptance model. Information \& Management 40 (3), 191-204.

Lessem, R., Neubauer, F., 1994. European Management Systems. McGraw-Hill, London.

Liebenau, J., Smithson, S., 1991. Editorial. European Journal of Information Systems 1 (1), 1-2.

Lou, H., Luo, W., Strong, D., 2000. Perceived critical mass effect on groupware acceptance. European Journal of Information Systems 9 (2), 91-103.

Lucas, H.C., Spitler, V.K., 1999. Technology use and performance: a field study of broker workstations. Decision Sciences 30 (2), 291-311.

Ma, Q., Liu, L., 2004. The technology acceptance model: A meta-analysis of empirical findings. Journal of Organizational and End User Computing 16 (1), 59-72.

Mathieson, K., 1991. Predicting user intentions: comparing the technology acceptance model with the theory of planned behavior. Information Systems Research 2 (3), 173-191.

Mathieson, K., Peacock, E., Chin, W.W., 2001. Extending the technology acceptance model: the influence of perceived user resources. The Data Base for Advances in Information Systems 32 (3), 86.

Meyers-Levy, J., Maheswaran, D., 1991. Exploring the differences in males' and females' processing strategy. Journal of Consumer Research 18, 63-70.

Minton, H.L., Schneider, F.W., 1980. Differential Psychology. Waveland Press, Prospect Heights, IL.

Moon, J.W., Kim, Y.G., 2001. Extending the TAM for a World-WideWeb context. Information \& Management 38 (4), 217-230.

Moore, G.C., Izak, B., 1991. Development of an instrument to measure the perception of adopting an information technology innovation. Information Systems Research 23 (3), 192-222.

Morris, M.G., Venkatesh, V., 2002. Age-differences in technology adoption decisions - implications for a changing work-force. Personnel Psychology 53 (2), 375-403.

Myers, M.D., Tan, F., 2002. Beyond models of national culture in information systems research. Journal of Global Information Management 10 (1), 24-32.

Orlikowski, W.J., 1993. Case tools as organizational change: investigating incremental and radical changes in systems development. MIS Quarterly 17, 309-341.

Segars, A.H., Grover, V., 1993. Re-examining perceived ease of use and usefulness: a confirmatory factor analysis. MIS Quarterly 17 (4), 517-525.

Short, J., Williams, E., Christie, B., 1976. The Social Psychology of Telecommunications. Wiley, London.

Siau, K., Sheng, H., Nah, F., 2003. Development of a framework for trust in mobile commerce. The Second Pre-ICIS Annual Workshop on HCI Research in MIS, Seattle, WA. 
Straub, D., Keil, M., Brenner, W., 1997. Testing the technology acceptance model across cultures: a three country study. Information \& Management 33 (1), 1-11.

Subramanian, G.H., 1994. A replication of perceived usefulness and perceived ease of use measurement. Decision Sciences 25 (5-6), 863-874.

Sun, H., Zhang, P., 2004. A methodological analysis of user technology acceptance. 37th Hawaii International Conference of System Science, Big Island, Hawaii.

Szajna, B., 1994. Software evaluation and choice: predictive validation of the technology acceptance instrument. MIS Quarterly 18 (3), 319-324.

Szajna, B., 1996. Empirical-evaluation of the revised technology acceptance model. Management Science 42 (1), 85-92.

Taylor, S., Todd, P.A., 1995a. Assessing IT usage: the role of prior experience. MIS Quarterly 19 (4), 561-570.

Taylor, S., Todd, P.A., 1995b. Understanding information technology usage: a test of competing models. Information Systems Research 6 (2), 144-176.

Teo, T.S.H., Lim, V.K.G., Lai, R.Y.C., 1999. Intrinsic and extrinsic motivation in Internet usage. Omega 27 (1), 25-37.

Thompson, R.L., Higgins, C.A., Howell, J.M., 1991. Personal computing toward a conceptual model of utilization. MIS Quarterly 15 (1), 125-136.
Triandis, H.C., 1980. Values, attitudes, and interpersonal behavior. Nebraska Symposium on Motivation, Beliefs, Attitudes, and Values. University of Nebraska Press, Lincoln, NE, pp. 195-259.

Venkatesh, V., 2000. Determinants of perceived ease of use: integrating control, intrinsic motivation, and emotion into the technology acceptance model. Information Systems Research 11 (4), 342-365.

Venkatesh, V., Brown, S.A., 2001. A longitudinal investigation of personal computers in homes: adoption determinants and emerging challenges. MIS Quarterly 25 (1), 71-102.

Venkatesh, V., Davis, F.D., 1996. A model of the antecedents of perceived ease of use: development and test. Decision Sciences 27 (3), 451-481.

Venkatesh, V., Davis, F., 2000. A theoretical extension of the technology acceptance model: four longitudinal field studies. Management Science 46 (2), 186-204.

Venkatesh, V., Morris, M.G., 2000. Why don't men ever stop to ask for directions? Gender, social influence, and their role in technology acceptance and usage behavior. MIS Quarterly 24 (1), 115-139.

Venkatesh, V., Morris, M.G., Davis, G.B., Davis, F.D., 2003. User acceptance of information technology: toward a unified view. MIS Quarterly 27 (3), 425-478.

Viswanath, V., Davis, F.D., 2000. A theoretical extension of the technology acceptance model: four longitudinal field studies. Management Science 46 (2), 186-204. 